\title{
Caspar, an adapter for VAP and TER94 delays progression of disease by regulating glial inflammation in a Drosophila model of ALS8
}

Shweta Tendulkar ${ }^{1}$, Sushmitha Hegde ${ }^{1, \#, ~ A p a r n a ~ T h u l a s i d h a r a n ~}{ }^{1, \#}$, Lovleen Garg ${ }^{1, \#}$, Bhagyashree Kaduskar $^{1}$, Anuradha Ratnaparkhi ${ }^{2}$, Girish S Ratnaparkhi ${ }^{1, *}$

${ }^{1}$ Indian Institute of Science Education \& Research (IISER) Pune 411008, INDIA

${ }^{2}$ Agharkar Research Institute, Pune 411004, INDIA

"Equal Contribution

*Author for Correspondence

Email: : girish@iiserpune.ac.in

ORCID IDs: Shweta Tendulkar (0000-0001-9305-7169), Sushmitha Hegde (0000-0003-0777-962X), Aparna Thulasidharan (0000-0003-4428-3308), Lovleen Garg (0000-0003-3592-0440), Bhagyashree Kaduskar (0000-0002-8506-1309), Anuradha Ratnaparkhi (0000-0001-6548-6185), Girish S

Ratnaparkhi (0000-0001-7615-3140).

Keywords: Amyotrophic Lateral Sclerosis, Proteostasis, FAF1, NFkappa B

This PDF file includes:

Main Text

Figures 1 to 5

Supplementary Figures: 5 


\section{ABSTRACT}

Amyotrophic Lateral Sclerosis (ALS) is a fatal, late onset, progressive motor neurodegenerative disorder. We have been studying cellular and molecular mechanisms involved in ALS using a vesicleassociated membrane protein-associated protein B (VAPB/ALS8) Drosophila model, which mimics many systemic aspects of the human disease. Here, we show that the ER resident VAPB interacts with Caspar, an ortholog of human fas associated factor 1 (FAF1). Caspar, in turn, interacts with transitional endoplasmic reticulum ATPase (TER94), a fly ortholog of ALS14 (VCP/p97, Valosin-containing protein), via its UBX domain and poly-ubiqutinated proteins with its UBA domain. Caspar overexpression in the glia extends lifespan and also slows the progression of motor dysfunction in the ALS8 model, a phenomenon that we ascribe to its ability to restrain age-dependant inflammation, modulated by Relish/NFKB signalling.

We hypothesize that Caspar is a key molecule in the pathogenesis of ALS. Caspar connects the plasma membrane (PM) localized immune signalosome to the ER based VAPB degradative machinery, presumably at PM:ER contact sites. The Caspar:TER94:VAPB complex appears to be a strong candidate for regulating both protein homeostasis and NFKB signalling. These, in turn, regulate glial inflammation and determine progression of disease. Our study projects human FAF1 as an important protein target to alleviate the progression of motor neuron disease. 


\section{INTRODUCTION}

Amyotrophic Lateral Sclerosis (ALS) is a human neurodegenerative disease that leads to the death of motor neurons. This disorder usually affects individuals late in life, with $90-95 \%$ cases being 'sporadic', indicating that the disease is not inherited. In about $5-10 \%$ of cases the disease is 'familial', where the disease is inherited across generations (CLEVELAND AND ROTHSTEIN 2001; PASINELLI AND BROWN 2006; MITCHELL AND BORASIO 2007). Despite the discovery of SOD1 as the first familial locus for ALS nearly three decades ago in 1993 (DENG et al. 1993; ROSEN et al. 1993), and the large volume of work, an understanding of the mechanistic aspects of disease initiation and progression has been elusive. One major reason for the delay has been the identification of more than two dozen ALS causative loci in humans, with each locus being distinct and unrelated to each other in terms of their physiological function (ABEL et al. 2012; ROBBERECHT AND PHILIPS 2013). For example, SOD1/ALS1 is primarily a regulator of cytoplasmic Reactive Oxygen Species (ROS), Senataxin (SETX)/ALS4 (CHANCE et al. 1998) works as a RNA or DNA helicase, FUS/ALS6 (VANCE et al. 2009) is a transcriptional activator, VAPB/ALS8 (NISHIMURA et al. 2004) is an ER membrane resident single pass protein that helps maintain intracellular membrane contact sites, while KIFA/ALS25 (NICOLAS et al. 2018) is a microtubule based motor protein. Nonetheless, specific mutations in each of these genes leads to development of the disease. Whether the pathway leading to motor neuron death is distinct for each locus or is caused by convergence to a common downstream cellular mechanism is not completely clear. A universal mechanistic model for the disease should be able to explain the convergence to the common end point, by incorporating a related set of cellular pathways that are perturbed by each of the causative loci. This would presuppose that subsets of ALS causing genes are connected, being part of genetic sub-network(s) in the cell, regulating common or overlapping physiological functions. If true, then it should be possible to uncover genetic relationships between different ALS loci and link these interactions to a set of common cellular pathways. This is best done in animal models where genetic tools to elucidate such interactions exist. In the past decade many such interactions have been discovered and cellular themes underscored. For example, multiple ALS loci have been found to be involved in functions related to RNA metabolism. These include TDP-43, FUS, ATXN2, TAF15, EWSR1, hnRNPA1, hnRNPA2/B1, MATR3 and TIA1. Another common theme is proteostasis, involving both production of proteins - TARDBP, FUS, TAF15 as well as degradationVCP, SQSTM1, UBQLN2, OPTN, and CCNF. Finally, vesicular transport, another potential fault line for ALS, involves C9ORF72, VAPB, OPTN, CHMP2B, PFN1, TUBA4A, ANXA11, ATXN2, NEFH, $P R P H, S P G 11$, SIGMAR1, GRN, DCTN1, KIF5A and ALSIN. Further support for the genetic subnetwork hypothesis is the finding that ALS is in all possibility a polygenic disease with several genes contributing to initiation and progression in both sporadic (SALS) and familial (fALS) cases (VAN BLITTERSWIJK et al. 2012; LEBLOND et al. 2014; RENTON et al. 2014).

VAPB was the $8^{\text {th }}$ fALS locus to be discovered (NISHIMURA et al. 2004) and has been used to model the disease in both invertebrates (PENNETTA et al. 2002; TSUDA et al. 2008; HAN et al. 2012; MOUSTAQIM-BARRETTE et al. 2014) and vertebrates (TEULING et al. 2007; LARROQUETTE et al. 2015). VAPB is a ubiquitous, tail anchored ER protein, enriched in contact sites where ER is juxtaposed with other intracellular membranes (reviewed by (LEV et al. 2008; MURPHY AND LEVINE 2016; KAMEMURA AND CHIHARA 2019)). VAPB associates with a number of partner proteins, re-enforcing membranemembrane distance and architecture (KAMEMURA AND CHIHARA 2019) and also assisting in roles performed by its numerous interacting partners (MURPHY AND LEVINE 2016; KAMEMURA AND CHIHARA 2019). Recent studies have focused on elucidation of specific roles for VAPB with each individual partner protein (LINDHOUT et al. 2019; MAO et al. 2019; CABUKUSTA et al. 2020; DI MATTIA et al. 2020), broadening our understanding of the workings of the VAPB network.

We have previously sought to uncover the gene regulatory network for the Drosophila ortholog of human VAPB, VAP33A/CG5014 (VAP here onwards) and to understand genetic relationships between ALS loci through an enhancer-suppressor screen (DEIVASIGAMANI et al. 2014). The study identified ALS orthologous loci (SOD1, Alsin, TDP43) as part of the VAP genetic network and also suggested an interaction with members of the Target of Rapamycin (TOR) signalling 
pathway (DEIVASIGAMANI et al. 2014). We subsequently explored the genetic relationship between $V A P$ and SOD1 and found that SOD1 regulation of cellular reactive oxygen species (ROS) levels led to a modulation of VAP ${ }^{P 58 S}$ aggregates (CHAPLOT et al. 2019), by triggering clearance of cellular inclusions via the ubiquitin-proteasomal system (UPS). In the current study, we explore the relationship between VAP and Transitional endoplasmic reticulum (ER) ATPase (TER94/ALS14; or p97, also called valosin containing protein, VCP). The decision to explore this relationship in detail was based on a targeted, tissue specific genetic screen, described here, carried out in muscles, glia and motor neurons.

In our study, we find that Caspar, an ortholog of human Fas associated factor 1 (FAF1)(CHU et al. 1995; RYU et al. 2003) is a physical interactor of both VAP and TER94 (KANG AND YANG 2011; KIM et al. 2011; BARON et al. 2014). We show that Caspar acts as a protein bridge, physically connecting VAP and TER94, that are orthologs of human VAPB/ALS8 and VCP/ALS14 respectively. Interestingly, increased Caspar expression in glia can improve the lifespan of our ALS8 disease model and can also delay the onset of motor dysfunction. The VAP:Caspar:TER94 complex appears to be a component of the ER -associated degradation (ERAD) network, with Caspar regulating the progression of the disease by modulating NFKB signalling. Our findings suggest that Caspar in glia plays a key role in disease progression by regulating age dependant glial inflammation thus highlighting the contribution of non-autonomous players in the development of the disease.

\section{RESULTS}

\section{A tissue specific enhancer/suppressor screen suggests genetic interactions between VAP and Drosophila orthologs of ALS loci.}

In the past we (RATNAPARKH et al. 2008; DeIVASIGAMANI et al. 2014; YADAV et al. 2018; CHAPLOT et al. 2019) and others (PENNETTA et al. 2002; CHAl et al. 2008; TsUDA et al. 2008; HAN et al. 2012; FORREST et al. 2013; SANHUEZA et al. 2015) have used VAP ${ }^{\mathrm{P} 88 \mathrm{~S}}$ overexpression models to understand mechanisms of disease. Here, for our experiments, we chose a ALS8 disease model developed by Hiroshi Tsuda's laboratory (MOUSTAQIM-BARRETTE et al. 2014), where an endogenous genomic-VAP ( $g V A P$ or $g V A P^{P 58 S}$ ) insert on the third chromosome is used to rescue the lethality of the VAP null $(\triangle V A P)$. The Tsuda disease model, $\triangle V A P ; g V A P^{P 58 S}$, unlike the control $\triangle V A P ; g V A P^{W T}$, has a shorter lifespan, shows progressive motor dysfunction, has VAP ${ }^{P 58}$ inclusions in the brain with cells showing ER expansion and ER stress (MOUSTAQIM-BARRETTE et al. 2014). In our laboratory, we have regenerated the Tsuda model, using the VAP 166 allele instead of the VAP $\triangle 31$ (See Materials \& Methods) and have used this for our studies.

In order to study the genetic relationships between VAP and different ALS loci, we chose six Drosophila genes, each being an ortholog of a major fALS locus (Fig. 1A). The genes chosen are fly orthologs of human TARDBP/ALS10, FUS/ALS6, SOD1/ALS1, VCP/ALS14 and SETX/ALS4, respectively. For each gene, transgenic lines for overexpression $(O E)$ and knockdown $(K D)$ experiments were procured (See Materials \& Methods). The goals of our experiments were twofold: first to test interactions between each gene and VAP using the disease model as a readout. Second, to explore these genetic interactions in the three tissues central to motor neuron disease, namely Neurons, Muscle and Glia. These experiments were driven by the concept that in addition to neuronal cells, non-neuronal cells (BOILLEE et al. 2006) also contribute to the disease. Three drivers were chosen, one for each tissue, myosin heavy-chain (MHC)-Gal4 for muscle, reverse polarity (Repo)Gal4 for glia and OK6-Gal4 for motor-neuron specific expression.

Gal4 drivers for glia, muscle and neurons with insertions in the second chromosome were balanced with $\triangle V A P$ and $g V A P^{P 58 S}$ to generate the following lines: $\triangle V A P ; R e p o-G a l 4 ; g V A P^{P 58 S}$, $\triangle V A P ;$ OK6-Gal4; $g V A P^{P 58 S}, \triangle V A P ; M H C-G a l 4 ; g V A P^{P 58 S}$ (Fig. 1A). Females of these driver lines were crossed to OE or KD(RNAi) lines of VAP, TBPH, FUS, SOD1, TER94, ALSIN and SETX. Adult 
males in the F1 generation, which lacked functional VAP on the $\mathrm{X}$ chromosome ( $\triangle V A P$; Fig. 1B) were collected and subjected to lifespan analysis as described (Materials \& Methods). Survival graphs for each cross are shown (Suppl. Fig. 1; Representative graphs in Fig. 1C), with a summary tabulated in Fig. 1D. Statistical analysis using the Log-Rank Test, as detailed in Materials and Methods, were used to compare experimental lifespan curves with controls and change $(\Delta)$ in median lifespan $(\mathrm{ML})$ was used as a simple parameter to reflect increase $(+)$ or decrease $(-)$ in lifespan (Fig. 1D).

A summary of results (Fig. 1D) of the differential lifespan analysis (data in Suppl. Fig 1), is as follows. In the muscle, both decrease or increase of activity of the genes tested seems to enhance the phenotype with a concomitant decrease of ML. In glia, increased activity of most of the genes (VAP, SOD1, TER94 and alsin) tested, seems to enhance the phenotype with a decrease of ML. In the KD studies, VAP and TBPH lead to decrease in ML while for other genes, the changes in lifespan were not very significant. In neurons, the overall trend pointed to a suppression of the phenotype, with increase in ML for knockdown of VAP, TBPH, caz and alsin. SOD1 OE, as also alsin OE led to a mild suppression of the phenotype. For most other genes, the effect was not significant $(p>0.05)$. The strongest enhancement of the lifespan phenotype was for TER94 OE with a $\triangle \mathrm{ML}$ ranging from 7-10 days; TER94 KD, in contrast, did not influence the lifespan of the $\triangle V A P / Y$; Repo-Gal4/+; gVAPP58S/+ line significantly (Fig. 1C,D). We chose to further explore, in greater detail, the TER94:VAP interaction, using our disease model. This direction was supported by a study from Gabriela Alexandru's group (BARON et al. 2014), which suggested that VAPB and VCP could interact physically in mammals via FAF1. As a first step, we conducted affinity purification experiments using fly lysates to test if VAP was a physical interactor of Caspar and if so, whether Caspar could be a potential adapter for the VAP:TER94 interaction in our disease model.

\section{Caspar is a physical interactor of both VAP and TER94}

A sequence comparison of Caspar with FAF1 finds that both proteins are of similar size, have the same domain structure (Fig. $2 \mathrm{~A}$ ) and on sequence alignment show $54 \%$ sequence similarity overall with $\sim 34 \%$ identity. Like its mammalian ortholog, Caspar contains well characterized, $\mathrm{N}$ terminal, Ubiquitin associated (UBA; SM00165) domain, known to interact with poly-ubiquitinated proteins and a C-terminal 'Ubiquitin regulatory X' UBX domain (SM00166), a known VCP/TER94 interactor (YEUNG et al. 2008). As detailed earlier (BARON et al. 2014), the Caspar superfamily is conserved from flies to humans and incorporates a variant of FFAT, 'two phenylalanines in an acidic tract' motif, EFFDAxE, (LOEWEN et al. 2003; LOEWEN AND LEVINE 2005). It is well established that this motif mediates interaction with VAP (LOEWEN AND LEVINE 2005; MURPHY AND LEVINE 2016; YADAV et al. 2018). Consistent with this, deletion or modification of this motif led to disruption of the FAF1:VAPB interaction (BARON et al. 2014). This strongly suggests that Drosophila Caspar, which contains a similar highly conserved FFAT motif (Fig. 2A, lower panel, Underlined) may also be a VAP interactor.

To test the VAP:Caspar interaction, we used an anti-Caspar antibody developed in our laboratory, as described in materials \& methods, to immuno-precipitate (IP) Caspar and its interactors. The anti-Caspar antibody specifically recognizes a $\sim 85 \mathrm{kD}$ band in adult whole animal lysates (Suppl. Fig. 2A), which is not seen in lysates of homozygous casparlof animals (Suppl. Fig. 2A). The anti-Caspar antibody IPs could enrich Caspar, as visualized by Western Blotting (Fig. 2B; *, Top panel) and could also pull down VAP (Fig. 2B; **, Bottom panel). To identify other Caspar interactors, we processed the Caspar IPs from adult and embryonic lysates through a Mass Spectrometer and found that Caspar associates with cytoplasmic proteins involved in protein folding/unfolding and ubiquitin mediated degradation (Fig. 2C, Suppl. Fig. 2D). In embryonic lysates, which is a rich source of Caspar, VAP is found as the second most enriched protein (after TER94), based on peptide count. In fly head extracts, the anti-Caspar antibody enriches both Caspar (Fig. 2D; ${ }^{*}$, top panel) and VAP (Fig 2D; ${ }^{* *}$, bottom panel). Further support for the VAP:Caspar interaction comes from a 'reverse IP' experiment in fly heads, where a VAP IP could pull down Caspar (Suppl. Fig. 2C). The VAP:Caspar physical interaction and the list of associated proteins such as TER94, Ufd1-like and Npl4 gives credence to the idea that Caspar acts as an adapter to bring together VAP 
and TER94 for an important physiological function, possibly related to protein homeostasis and degradation. Caspar is thus a bona-fide interactor of both VAP and TER94, and this protein complex is conserved from flies (VAP:Caspar:TER94) to humans (VAPB:FAF1:VCP; (BARON et al. 2014)).

\section{Expression of Caspar in the glia extends lifespan}

The existence of a VAP:Caspar:TER94 complex in flies suggests that TER94 and Caspar may have common or overlapping physiological roles. In order to uncover these we expressed two ALS fly variants of TER94, TER94 ${ }^{A 229 E}$ and TER94 ${ }^{R 152 H}$ (RITSON et al. 2010; CHANG et al. 2011) in the glia, muscle and neurons. Expression of TER94 ${ }^{R 152 H}$ led to a significant extension of lifespan $(\Delta \mathrm{ML}=+4.5)$ when expressed in glia, but not in muscle $(\Delta \mathrm{ML}=-2)$ or neurons $(\triangle \mathrm{ML}=+2)$. TER94 ${ }^{\mathrm{A} 229 E}$ expression in the glia was lethal and adult flies did not emerge (Fig. 3A). R152 is located in the Nterminal CDC48 domain of TER94 and R152H is classified as a dominant active allele (CHANG et al. 2011; ZHANG et al. 2015). The N-terminal domain of TER94 is also known to interact with UBX domains, suggesting that the mutation may modulate the strength or dynamics (ZHANG et al. 2015) of the TER94:Caspar interaction. In order to test the effect of $O E$ and $K D$ of Caspar in glia, we procured a RNAi line for caspar (UAS-caspar ${ }^{R N A i}$ ) and also generated UAS-caspar lines (See Materials \& Methods). $\triangle V A P$; Repo-Gal4/+; gVAP P58S/UAS-caspar ${ }^{R N A i}$ males had a shorter lifespan $(\triangle \mathrm{ML}=-4.0)$ when compared to the disease model, $\triangle V A P / Y$; Repo-Gal4/+; $g V A P^{P 58 S /+}$ (Fig $\left.3 \mathrm{~A}, \mathrm{~B}\right)$. Intriguingly, overexpression of caspar in the glia ( $\triangle V A P$; Repo-Gal4/+; gVAPP58S/UAS-caspar), significantly increased lifespan $(\triangle \mathrm{ML}=+7.5)$ (Fig. $3 \mathrm{~B})$ of the disease model. In repeat experiments, $\Delta \mathrm{ML}$ ranged from 7-9 days, with the extension of lifespan always greater than the ( $\triangle V A P ; R e p o-G a l 4 /+$; $g V A P^{P 58 S} / U A S-T E R^{\mathrm{R} 152 \mathrm{H}}$ ) experiment, where the $\triangle \mathrm{ML}$ ranged from 4-6 days. The dramatic increase was made even more significant because overexpression of caspar in a wild-type background (Fig. 3 $C, D)$ severely shortened lifespan $(\Delta M L=-17)($ Fig. $3 D)$, while caspar $K D$ increased lifespan $(\Delta M L=+4)$. For TER94, both $O E$ and $K D$ decreased $\mathrm{ML}$, in wild-type animals, by 3.5 and 9 days respectively, pointing to the importance of maintaining homeostatic levels of TER94 in the glia. Thus, the increased lifespan seen after TER $94^{R 152 H}$ and caspar ${ }^{W T}$ glial $O E$ strongly suggests an important physiological role for the VAP:Caspar:TER94 complex in our disease model.

\section{Expression of Caspar in the glia delays age dependant motor deterioration.}

The $\triangle V A P ; g V A P^{P 58 S}$ fly line develops progressive motor defects (MOUSTAQIM-BARRETTE et al. 2014)(Fig. 3E). Since OE of both the TER94 ${ }^{R 152 H}$ and caspar increase the lifespan of the VAP ${ }^{P 58 S}$ disease model, we measured the changes seen in motor activity, using the ability of flies to climb as a readout. The data were measured and analysed as described (Materials \& Methods) and displayed in in terms of a climbing index (Fig. 3E,F). caspar overexpression significantly improved motor function (Fig. 3E, 5-red line), when compared to the control (Fig. 3E, 1-dark blue curve). TER94 ${ }^{R 152 H}$ OE also showed a mild improvement in motor function, at par with TER94 KD. In comparison, when expressed in a wild-type fly, motor function did not improve for any of the genotypes (Fig. 3F) tested, with the possible exception of TER94 OE (Fig. 3F, 2- Dark green curve). For a better appreciation of the agedependence of motor function, we have plotted the data at five day intervals (Fig. 3G,H; Suppl. Fig. $3 A, B)$. In Fig. $3 \mathrm{G}, \mathrm{H}$ the statistical significance is color coded, with yellow, orange and red signifying deterioration of motor function, and shades of green indicating improvement in motor function, for animals of equivalent age. For the disease model (Fig 3G), in the age group 10-20 days, there appears to be a significant improvement of motor function for TER94 ${ }^{R 152 H}, T E R 94 K D$ and caspar OE. In contrast, overexpression of TER94 ${ }^{W T}$ and caspar RNAi led to a significant deterioration of motor function for flies aged 20 and 25 days. For wild type flies, TER $94^{W T}$ OE was detrimental for motor function after 25 days (Fig. 3H).

Both the lifespan and motor dysfunction data suggest that the VAP:Caspar:TER94 complex in glia may be an important contributor for the progression of the disease. TER94 is an important member of the UPS, that leads to proteasomal degradation of proteins (YEUNG et al. 2008; VAN DEN BOOM AND MEYER 2018). With Caspar having an ability to coordinate transfer of ubiquitinated proteins to TER94, 
and with VAP acting as a docking site for Caspar, there is a strong possibility that these proteins cooperate in a physiological function that is related to proteostasis. This common function may be the Endoplasmic-Reticulum Associated Degradation (ERAD)(RUGGIANo et al. 2014; FRAKES AND DILLIN 2017) or clearance of VAPP58S inclusions/ aggresomes (CHAPLOT et al. 2019). To confirm the same, we measured the change in the inclusion status of VAP aggregates in the brain of the adult fly, in response to caspar overexpression, in an age dependant manner.

\section{Caspar expression does not modulate VAP ${ }^{\mathrm{P} 58}$ inclusions in the adult brain.}

In an earlier study, working with the larval brain, we had uncovered the physiological basis of the genetic interaction between SOD1/ALS1 and VAPIALS8 (DEIVASIGAMANI et al. 2014; CHAPLOT et al. 2019). Cellular Reactive Oxygen Species (ROS), when increased in response to SOD1 malfunction triggered proteasomal activity, which led to a clearance of VAP ${ }^{\mathrm{P} 58 \mathrm{~S}}$ aggregates from brain cells. The density of VAP ${ }^{\mathrm{P} 8 \mathrm{~S}}$ inclusions in the brain was measured and found to decrease significantly with increase in cellular ROS (CHAPLOT et al. 2019). A similar methodology was developed to measure aggregates in the adult fly brain of the disease model. Interestingly, the density or area of VAP inclusions in the brain did not increase or decrease significantly on caspar OE or even caspar KD in the glia (Fig 4), in both larval (Suppl. Fig. 4) and adult brains (Fig. 4). This would suggest that increased lifespan and improved motor function that we see are not related to the 'average' density or size of VAP ${ }^{\mathrm{P} 8 \mathrm{~S}}$ inclusions, which can be visualized by microscopy. This suggests that the VAP:Caspar:TER94 function that we are attempting to elucidate may either modulate proteostasis of proteins other than VAP inclusions or it may suggest that the complex has other, unknown functions in the cell. Results similar to ours have been found in a mammalian cell culture model (GENEVINI et al. 2014).

The only known function in fly literature for Caspar is that it is a regulator of NFKB signalling (KIM et al. 2006). Caspar negatively regulates Immune Deficient (IMD)/NFKB signalling by controlling activity of the protease Death related ced-3/Nedd2-like caspase (Dredd), a Caspase-8 ortholog (LEULIER et al. 2000; STOVEN et al. 2000), which in turn cleaves the full-length precursor Relish (Rel), a fly NFKB, which is sequestered in the cytoplasm. FAF1 (MENGES et al. 2009) has similar roles in NFKB signalling (MIN-YOUNG et al. 2004; PARK et al. 2007), negatively regulating signalling by influencing the IKB kinase (IKK) complex. Overexpression of FAF1 in Jurkat cells causes cell death, a phenomenon that is dependent on its interaction with Fas associated death domain (FADD) and Caspase-8 (RYu et al. 2003). Dredd was itself discovered as a novel effector for apoptosis (CHEN et al. 1998) and is a FADD interactor (HU AND YANG 2000). Cleavage of Rel generates an N-terminal 68 $\mathrm{kD}$ polypeptide (REL68) that can be transported to the nucleus and transcriptionally activate defence genes. Increase in Caspar activity leads to reduction in IMD signalling while absence of Caspar leads to hyper-activation of IMD signalling and hence inflammation (KIM et al. 2006), in immune cells. A possible hypothesis for our disease model is that Caspar activity or levels may regulate import of REL68 in the glia, and that increased inflammation in the disease model, a consequence of reduced Caspar function may lead to a shorter lifespan and decreased motor function. If this hypothesis is true then two conditions need to be met. First, there should be increased inflammation in the disease model, especially for older flies, when compared to controls and second, the modulation of IMD/Rel signalling in glia should reduce or enhance the progression of the disease.

\section{Progression of ALS8 is modulated by the extent of glial inflammation.}

Healthy ageing in Drosophila includes the age-dependant upregulation of the immune response (KOUNATIDIS et al. 2017), regulated by the IMD/Rel pathway and is strongest in the fly head (KOUNATIDIS et al. 2017). We measured inflammation in the brain by measuring the levels of mRNA for Imd/Rel targets such as attacinD, diptericin, drosocin and cecropinA1 and a Toll/Dif target metchnikowin, in the dissected heads of adult Drosophila, as a function of age. On day 5, $\triangle V A P$; Repo>+; gVAP ${ }^{P 85}$ heads had diptericin and attacinD levels with higher averages, but not statistically significant. For 5-day old animals, drosocin and cecropinA1 levels were significantly higher than 
controls (Fig 5A). For 15-day old animals, where the disease had progressed, for diptericin, drosocin and cecropinA1, there is a 2-4-fold increase in mRNA levels as compared to controls. For attacinD, diptericin and drosocin, overexpression of caspar in the glia reduces levels of these antimicrobial peptide genes, by $\sim 2$-fold. metchnikowin, a target of Toll signalling does not show age dependant inflammation and is not influenced by caspar overexpression (Fig 5A). Thus, on the $15^{\text {th }}$ day, with disease onset well underway, and with $\sim 80 \%$ of the animals still alive, there was a significant increase of inflammation in the head, which was reined in by Caspar.

To test the second prediction, we modulated the levels of IMD/Rel signalling to upregulate or downregulate glial inflammation. Enhanced inflammation should lead to a reduction in ML and reduction of inflammation should increase the $\mathrm{ML}$ of the disease model. First, we measured the change in lifespan of $\triangle V A P ; R e p o>+; g V A P^{P 58 S}$ flies after overexpressing and knocking down Rel, the transcriptional effector of the IMD/Rel pathway. Rel OE leads to increased inflammation and reduced lifespan by $\sim 6$ days (Fig. $5 \mathrm{~B}, \mathrm{C})$. KD of Rel by RNAi or reduction of $R e l$ by $\sim 50 \%\left(R e l^{E 20} /+\right)$, increased $\triangle \mathrm{ML}$ by $\sim 4$ days (Fig. $5 \mathrm{~B}, \mathrm{C}$ ). Next we tested other elements of the IMD/Rel pathway (Fig $5 \mathrm{E})$. Knockdown of $I M D, I R D 5$ and $P G R P-L C$ showed an enhancement in lifespan by 2-3 days (Fig. $5 C$ ), suggesting that these genes were part of a sterile inflammation cascade and/or a feedback loop. $O E$ of IRD5 decreased lifespan ( $\triangle \mathrm{ML}=-4$ ), while $O E$ of $P G R P-L C$ did not modulate lifespan, whereas $\mathrm{KD}$ of $P G R P-L E$ increased $\triangle \mathrm{ML}$ by 3 days. Knockdown of Dredd reduced lifespan $(\triangle \mathrm{ML}=-5)$. The Dredd result was unexpected as a reduction in Dredd activity should reduce Rel signalling and reduce inflammation. Control lifespan experiments (Suppl. Fig. 5; Fig. 5D), in wild type flies, demonstrate that both gain-of-function and loss-of-function of Rel activity shortens lifespan as does reduction of Dredd in the glia. Dredd loss of function may have a role in triggering cell death and influence inflammation. The single available Dredd RNAi stock (BDSC, 34070) appears to be a weak and sick stock, and this may also confound the data. Dredd resides on the $\mathrm{X}$ chromosome, which makes it challenging to use Dredd deficiencies for our male specific readout. Another possibility is that Rel cleavage in glia may be Dredd independent, with an alternative pathway used for Rel cleavage and import. For example, in mammals, NFKB cleavage and maturation is a function of the proteasome (SEARS et al. 1998), rather than a Dredd ortholog. Caspar, like FAF1 in mammals may directly bind to and influence Rel maturation.

In summary, IMD/Rel signalling (reviewed by (LEMAITRE AND HOFFMANN 2007; LIGOXYGAKIS 2013; MYLLYMAKI et al. 2014; ZHAl et al. 2018)), in the glia, appears to play a major role in regulating the lifespan of our disease model. Caspar can negatively regulate IMD/Rel signalling in glial cells and alleviates disease by reducing inflammation in the brain.

\section{DISCUSSION}

Over the past decade it has become apparent that NFKB signal transduction cascades have diverse roles in the brain (reviewed by (MEFFERT AND BALTIMORE 2005; BOERSMA AND MEFFERT 2008; KALTSCHMIDT AND KALTSCHMIDT 2009)). Major functions of NFKB signalling include the regulation of the neuronal immune response (NGUYEN et al. 2002; SOCHOCKA et al. 2017), learning and memory (LUBIN AND SWEATT 2007), neural development (AlBENSI AND MATTSON 2000; BEATTIE et al. 2002; Nickols et al. 2003; RoLLs et al. 2007) and neuronal cell death (CHINCHORE et al. 2012). In flies, the Toll/ NFKB pathway has been linked to regulation of post-synaptic GluRIIA levels (HECKSCHER et al. 2007) while the IMD/ NFKB signalling appears to have important behavioural, apoptotic (CHINCHORE et al. 2012) and neuro-inflammatory roles (CAO et al. 2013; PETERSEN et al. 2013; KoUNATIDIS et al. 2017; LI et al. 2018). In 2017, the Ligoxygakis lab (KouNATIDIS et al. 2017), found that IMD/NFKB signalling in the Drosophila brain was important for a normal lifespan, with negative regulators of IMD/NFKB playing critical roles in reducing inflammation in the brain. Enhanced inflammation was a key feature in agedependant neurological decline. Reduction of inflammation, specifically in the glia could reverse phenotypes associated with age dependant neurodegeneration. In agreement with this idea, lifespan in a fly model of SCA (LI et al. 2018), where SCA3 ${ }^{\text {polyQ78 }}$ was expressed in neurons, could be 
extended by reduction of IMD/Rel signalling. Earlier, in a SOD1 ${ }^{\mathrm{G} 93 \mathrm{~A}}$ mouse model for ALS, it was found that NFKB signalling is upregulated in spinal cords, a feature also seen in the same tissue in human patients (FRAKES et al. 2014). In the mouse model, cessation of NFKB activity (FRAKES et al. 2014) in microglia rescued motor neurons from early death and extended lifespan by reduction of inflammation. Glia have thus emerged as a cell type where NFKB has critical roles in both vertebrates and invertebrates (BAZAN 2009; KoUNATIDIS AND CHTARBANOVA 2018). C9orf72, a gene that is found to be perturbed in $60 \%$ of sALS patients appears to be required for proper macrophage and microglial function in mice (O'ROURKE et al. 2016). Also, NFKB signalling appears to be activated in both fALS and SALS (SWARUP et al. 2011). NF-KB, thus appears to be an important signalling pathway in the glia (ONEILL AND KALTSCHMIDT 1997; BeATTIE et al. 2002).

Our understanding of the mechanisms that fine tune IMD/Rel signalling has grown in leaps and bounds in the last decade (LEMAITRE AND HofFMANN 2007; MYLLYMAKI et al. 2014; KLEINO AND SILVERMAN 2019). An emerging theme in NFKB signal transduction is the detection of large cytoplasmic supramolecular protein complexes that undergo clustering with a evidence of amyloid formation and colloidal phase separation (DICKENS et al. 2012; Fu et al. 2016; KLEINO et al. 2017; KLEINO AND SILVERMAN 2019). These compartments increase the local concentration of the elements involved in signalling, and their formation and stability in response to immune signalling depends on dynamic post translational modifications (PTMs), with poly-ubiquitin chains playing a central role (ZHOU et al. 2005; PAQUeTTE et al. 2010; MEINANDER et al. 2012; CHEN et al. 2017), possibly offering docking sites for complex formation. A feature of the NFKB 'signalosome' is the clustering of IMD, FADD and Dredd at the PGRP-LC receptor, near the plasma membrane (PM). In Drosophila, the death effector domains and the death interaction domains are binding partners for the formation of one of the core components of the complex (HU AND YANG 2000; KLEINO AND SILVERMAN 2019). The association of IMD/Dredd/Caspar/FADD via these domains has critical roles in modulating signalling for both host defence and cell death (GEORGEL et al. 2001; CHINCHORE et al. 2012; KIM et al. 2014).

Our study puts the spotlight on Caspar and its role in the cell, potentially as adapter protein that connects plasma membrane (PM)-based PGRP-LC amyloid clusters to the VAP domain at the ER. An extension of the above idea would suggest that Caspar may perform its function in membrane contact sites (MCS), where the PM and ER are in close association (ZAMAN et al. 2020). VAP, itself is enriched in MCS, interacting with partner proteins in opposing membranes to maintain membrane: membrane spacing (MURPHY AND LEVINE 2016; YADAV et al. 2018). The spatially restricted MCS, along with the clustering of IMD/Rel pathway proteins would form an ideal compartment for regulated signalling. Intriguingly, VAP has earlier been identified as a physical interactor of Rel (FUKUYAMA et al. 2013). This study from the Hoffmann lab uncovered 369 protein:protein interactions in the IMD/Rel pathway, again underscoring the role of protein:protein interactions in IMD/Rel signaling. In the same study, Ird5 was found to be a conjugation target for the PTM, SUMO. The SUMO conjugation resistant variant Ird5 $5^{\mathrm{K} 152 \mathrm{~A}}$ was found not to be an efficient transducer of the immune signal. Caspar itself is SUMO conjugated at K551 (HANDU et al. 2015). In addition to ubiquitination and phosphorylation, SUMO conjugation may play an important role (HEGDE et al. 2020) in formation of signalosomes, especially with many of the proteins involved containing SUMO interaction motifs. The PM:ER MCS could serve as a domain where the VAP:Caspar:TER94 complex could associate with proteins that are part of the IMD/Rel signal transduction cascade. Caspar, with its ability to bind to poly-Ub proteins, to TER94 and to VAP has the potential to bring together VAP with functional elements of the proteasome and the NFKB signalosome.

An important question that remains is the molecular function of Caspar in the cell. Based on the available data there are two possibilities. One, Caspar may be a facilitator of protein degradation and in addition to assisting in VAP mediated protein degradation, it may regulate IMD/Rel signalling by actively degrading proteins, which would include targeting elements such as Dredd and Rel for degradation. The exact mechanism for regulation of Dredd by Caspar (KIM et al. 2006) has not been worked out and its degradative function may well be the answer. Two, Caspar may be an adapter that 
regulates the association of signalling complexes. For the second function, it may assist in capturing poly-Ub chains for modification of proteins in the signalosome. Activation via Ub-conjugation is a theme in activation of the pathway (PAQUETTE et al. 2010; MEINANDER et al. 2012). The Silverman and Meier labs have earlier documented mechanisms involved for K63-polyUb conjugation of IMD and Dredd by the E3-ligase DIAP2, along with the accessory proteins Effete, Bend and Uv1a, all of which are part of the complex (PAQUETTE et al. 2010; MEINANDER et al. 2012). Active control of IMD/Rel signalling may require ER:PM contact with many of the components discussed above involved in finetuning the signal.

Our model (Fig. 5E), which should parallel the onset and progression of disease in ALS incorporates the three major physiological events that are central to glial homeostasis. First, animals expressing VAP ${ }^{P 58}$, in the absence of wild-type VAP show ER stress (KANEKURA et al. 2009; MORI et al. 2011; MOUSTAQIM-BARRETTE et al. 2014; LARROQUETTE et al. 2015) and morphological changes in the ER (FASANA et al. 2010; KUIJPERS et al. 2013), a direct or indirect response to misfolded or partially-folded mutant VAP proteins. The fact that $V A P^{P 58 S}$ lines can progress through development, in the absence of $V A P^{W T}$, suggests that VAP ${ }^{P 58 S}$ is partially active, but this allelic variant is unable to sustain adult life beyond $\sim 25$ days. Second, the ER stress should lead to enhanced clearance by the UPS, with pathways such as ERAD (VEMBAR AND BRODSKY 2008), working overtime to maintain proteostasis. The evidence for VAP and Caspar's involvement in proteasomal clearance is primarily based on its interaction with TER94 and the presence of ERAD components Ufd1-like and Npl4 in Caspar IPs. This in turn could lead to overload at the proteasome (MoumEN et al. 2011), though experiments with CDC3 $\delta$ suggest otherwise (GENEVINI et al. 2014). Last, but not the least, there appears to be an age dependant increase in glial inflammation, which can be reined in by an increase in Caspar levels. This suggests that the pool of Caspar available to negatively regulate Rel is reduced in our ALS disease model. Logically, the reason for this decrease would be the sequestration of Caspar, either by VAP ${ }^{P 58 S}$ or by the strained proteasomal machinery.

In summary, we find that Caspar regulates disease progression, primarily by regulating inflammation in glia. VAP appears to function as a docking site for Caspar; Caspar connects not only two ALS orthologous loci, namely VAP and TER94, together, it also links these to IMD/Rel signalling. Caspar is therefore a point of convergence for critical cellular pathways that are central to motor neuron disease.

\section{MATERIALS \& METHODS}

Drosophila husbandry, Stocks and reagents: All flies were raised and crosses were conducted at 25 ${ }^{\circ} \mathrm{C}$ in standard corn meal agar. The flies expressing genomic VAP'T ( $g$ VAP ${ }^{P 58 S}$ (VK31)/TM3TB) and $V P^{P 58 S}$ ( $g V A P^{W T}$ (VK31)/TM3TB) were a kind gift from Hiroshi Tsuda (Moustaqim-Barrette et al., 2013). We balanced these with VAP $\triangle 166$, to generate $\triangle 166 / F M 7 A ;+;$ gVAPP58S (VK31)/TM3TB and $\triangle 166 / F M 7 A ;+; g V A P^{W T}$ (VK31)/TM3TB. The VAP $\triangle 166$ allele was used instead of VAP 31 used earlier because we were unsuccessful in receiving live $V A P \triangle 31$ flies from the Tsuda lab. VAP 166 (PENNETTA et al. 2002), like the VAPA31 allele, is a larval/pupal lethal. The primary lines used for our experiments, $\triangle 166 ;+; g V A P^{W T}$ and $\triangle 166 ;+; g V A P^{P 58 S}$ are at par with the Tsuda lines in terms of lifespan, cytoplasmic VAP inclusions and motor dysfunction.

Further, these lines were modified by adding Gal4 driver chromosomes for the second chromosome. The Gal4 drivers used were MHC-Gal4, OK6-Gal4 and Repo-Gal4. The UAS-VAPWT and UAS-VAPP58S were generated in the Jackson lab (RATNAPARKHI et al. 2008). Lines procured from the Bloomington Drosophila Stock Centre are: Name (Stock \#), Canton-S (0001), UAS-VAP ${ }^{R N A i}$ (27312), UAS-TBPH ${ }^{R N A i}(29517), U A S-$ caz $^{W T}$ (17010), UAS-caz ${ }^{R N A i}$ (34839), UAS-SOD ${ }^{W T}(24754)$, UAS-SOD1 ${ }^{\text {RNAi }}$ (34616), UAS-TER94 ${ }^{\text {RNAi }}$ (32869), UAS-alsin ${ }^{W T}$ (27162), UASalsin ${ }^{R N A i}$ (28533), UAS-senataxin RNAi (34683), MHC-Gal4 (38464), OK-Gal4 (64199), (UAScaspar $^{\text {RAA }}$ (44027), UAS-Rel RNAi (33661), UAS-Re/WT (9459), Relish ${ }^{E 20}$ (55714), UAS-Imd ${ }^{\text {RNAi }}$ (38933), 
$\operatorname{UAS}^{-i r d 5^{W T}}$ (90312), UAS-ird5 ${ }^{R N A i}$ (57751), UAS-Dredd ${ }^{R N A i}$ (34070), UAS-PGRP-LE ${ }^{R N A i}$ (60038), UASPGRP-LCWT(30919), UAS-caspar ${ }^{\text {RAAi }}$ (44027), casparlof (11373), caspar deficiency (23691. Lines procured from the National Institute of Genetics were UAS-Re/ ${ }^{11992 R-1}$ and UAS- Rel ${ }^{11992 R-2}$. The UASTBPH:FLAG:HAWT line was procured from the National Centre for Biological Sciences Stock Centre (NCBS,(DIAPER et al. 2013)), while UAS-TER94 ${ }^{W T}$, UAS-TER94 ${ }^{R 152 H}$, UAS-TER94 ${ }^{A 229 E}$ were procured from the Taylor laboratory (RITSON et al. 2010). Third chromosome apterous-Gal4 and daughterless Gal4 were procured from the Shashidhara laboratory. The second chromosome RepoGal4 (LEE AND JONES 2005), was a kind gift from Dr. Bradley Jones. UASt-caspar:HA was generated by procuring the cloned vector UFO05904 from the Drosophila Genomics Resource Centre taggedORF collection and generating transgenic animals at the NCBS transgenic facility. Expression of the line was validated by monitoring transcripts by real-time PCR and protein expression by anti-HA and anti-Caspar antibodies. The casparlof (casp ${ }^{\text {c04227}}$ ) line is a gypsy insert in the caspar locus and is a strong hypomorphic (near-null) allele (Suppl. Fig. 2A).

Lifespan and survival analysis: Survival assays were carried out on the genomic VAP ( $g$ VAP) lines (Fig $1 \mathrm{~A}$ ) and their derivatives (Suppl. Fig 1; Fig. 1D). For each experiment, $100 \mathrm{~F} 1$ male flies of the desired genotype were collected with each vial containing 15 or less age-matched flies. Animals were flipped to a fresh vial every fourth day, with number of flies recorded per vial on a daily basis, till all flies, including those in control experiments were dead. The survival data was plotted and analysed using the log-rank test in Prism 7, which compares the entire survival curve(s) and a gives a value of significance as a p-value, which was recorded and reported as a colour-coded map (Fig. 1D). The ML for each curve was also calculated and used as a simple readout for each experiment.

Generation of Caspar Antibody: Full length caspar was sub-cloned into pET-45b. The N-terminal 6XHis-Tagged Caspar was expressed in E. coli BL21DE3 cells. 1mM Isopropyl $\beta$-D-1thiogalactopyranoside was used to induce expression of protein at $25^{\circ} \mathrm{C}$. The cellular lysate, in $1 \mathrm{X}$ TBS, $10 \mathrm{mM}$ Imadizole was incubated with Ni-NTA beads (Qiagen) and the bound protein of interest was eluted using increasing concentrations of Imidazole, namely, $25 \mathrm{mM}, 50 \mathrm{mM}, 100 \mathrm{mM}, 150 \mathrm{mM}$. Caspar eluted at both 50 and $100 \mathrm{mM}$. The fractions were merged, concentrated and injected into a GE Healthcare Sephadex-G200 preparative column. Fractions of the major peak at $150 \mathrm{kDa}$ were collected and eluted protein showed a molecular weight of $66 \mathrm{kDa}$ in SDS-PAGE gels, suggesting that Caspar was a dimer in its native state. The column-purified protein was used to generate a Rabbit Polyclonal antibody by Bioklone (Chennai, India). The serum was further purified with Caspar conjugated to Protein A beads and the Caspar enriched IgG used for further experiments. The antibody was validated (Suppl. Fig. 2). The working dilutions for the antibody were 1:20,000 for Western Blots and 1:1000 for tissue.

Immunoprecipitation, Western Blot Analysis: 5-10 day old adult flies were lysed in Co-IP Lysis Buffer (20mM Tris pH 8.0, 137mM NaCl, 1\% IGEPAL, 2mM EDTA, 1X PIC) using a Dounce homogenizer and centrifuged at $21,000 \mathrm{~g}$ for 30 minutes. $3 \mathrm{mg}$ of total lysate was incubated with $5 \mu \mathrm{g}$ of primary antibody (Rb anti-Caspar or Rb anti-VAP) and $5 \mu \mathrm{g}$ of Normal Rabbit IgG overnight at $4{ }^{\circ} \mathrm{C}$. The AntiVAP antibody was generated as described (YADAV et al. 2018; CHAPLOT et al. 2019). Antigen-antibody complexes were captured using 50 $\mathrm{\mu l}$ of BioRad SureBeads Protein A (1614013) at $4{ }^{\circ} \mathrm{C}$ for 4 hours. Beads were washed six times with Co-IP Lysis Buffer and protein complexes eluted by boiling in $1 \mathrm{X}$ Laemmli Sample Buffer. Eluted proteins were resolved on a 10\% polyacrylamide gel followed by western blotting or in-gel trypsin digestion. Proteins separated by SDS-PAGE were transferred onto a PVDF membrane (Immobilon-E, Merck) and blocked in 5\% milk in Tris-Buffer Saline (TBS) with 0.1\% Tween 20 (TBS-T) for an hour. Blots were then incubated overnight with primary antibody diluted in $5 \%$ milk in TBS-T, at $4{ }^{\circ} \mathrm{C}$. Following three washes with TBS-T, blots were incubated with secondary antibodies diluted in $5 \%$ milk in TBS-T, for 1 hour at RT. Blots were washed thrice with TBS-T and visualized on a LAS4000 Fuji imaging system after incubating with Immobilon Western Chemiluminescent HRP substrate (Merck). The following antibodies were used: Rabbit anti-VAP, 1:10000 (YADAV et al. 2018; CHAPLOT et al. 2019); Mouse anti-a-Tubulin, 1:10000 (T6074, Sigma- 
Aldrich); Goat anti-rabbit HRP and Goat anti-mouse HRP secondary antibodies, each at 1:10000 (Jackson ImmunoResearch).

In-gel Trypsin Digestion and LC-MS/MS Analysis: Before in-gel trypsin digestion of the Co-IP eluate, the antibody was crosslinked to the SureBeads using DMP (Sigma) according to the NEB crosslinking

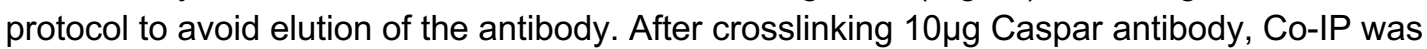
performed as described above. In-gel trypsin digestion was carried out as previously described (SHEVCHENKO et al. 2006). Briefly, Coomassie-stained bands on the gel were excised and cut into 1 $\mathrm{mm}$ cubes. Gel pieces were transferred to a clean microcentrifuge tube and destained with buffer containing $50 \%$ acetonitrile in $50 \mathrm{mM}$ Ammonium bicarbonate. Reduction and alkylation were carried out on the destained gel pieces by incubating with $10 \mathrm{mM}$ dithiothreitol (DTT) followed by incubating with $20 \mathrm{mM}$ iodoacetamide. Gel pieces were saturated with sequencing grade Trypsin (Promega) at a concentration of $10 \mathrm{ng} / \mu \mathrm{l}$ and incubated overnight at $37^{\circ} \mathrm{C}$. Peptides were extracted by sequential addition of $100 \mu \mathrm{l}$ of $0.4 \%$ Trifluoroacetic acid (TFA) in $10 \%$ ACN, $100 \mu \mathrm{l}$ of $0.4 \%$ TFA in $60 \%$ ACN and $100 \mu \mathrm{l}$ of ACN. The pooled extract was dried in a vacuum centrifuge and reconstituted with $50 \mu \mathrm{l}$ of $0.1 \%$ TFA. The peptides in TFA were purified using the StageTip protocol (RAPPSILBER et al. 2007).

LC-MS/MS analysis was performed on the Sciex TripleTOF6600 mass spectrometer interfaced with an Eksigent nano-LC 425. Tryptic peptides $(1 \mu \mathrm{g})$ were loaded onto an Eksigent C18 trap $(5 \mu \mathrm{g}$ capacity) and subsequently eluted with a linear acetonitrile gradient on an Eksigent $\mathrm{C} 18$ analytical column $(15 \mathrm{~cm} \times 75-\mu \mathrm{m}$ internal diameter). A typical LC run lasted $2 \mathrm{~h}$ post loading onto the trap at a constant flow rate of $300 \mathrm{~nL} / \mathrm{min}$ with solvent $\mathrm{A}$ consisting of water $+0.1 \%$ formic acid and solvent $B$ consisting of acetonitrile. The gradient schedule for the LC run was $5 \%$ (vol/vol) B for $10 \mathrm{~min}$, a linear gradient of B from $0 \%$ to $80 \%$ (vol $/ \mathrm{vol}$ ) over $80 \mathrm{~min}, 80 \%$ (vol $/ \mathrm{vol}$ ) B for $15 \mathrm{~min}$ and equilibration with $5 \%$ (vol/vol) B for $15 \mathrm{~min}$. Data was acquired in an information-dependent acquisition (IDA) mode over a mass range of $300-2,000 \mathrm{~m} / \mathrm{z}$. Each full MS survey scan was followed by MS/MS of the 15 most intense peptides. Dynamic exclusion was enabled for all experiments (repeat count 1; exclusion duration $6 \mathrm{~s}$ ). Peptide identification and quantification were carried out with the SCIEX ProteinPilot software at a false discovery rate (FDR) of $1 \%$. A RefSeq Drosophila protein database (release 6) was used for peptide identification. Proteins that were identified in two or more replicates and had two or more quantified peptides were tabulated.

Motor Function: Motor performance of each genotype was analyzed using the standard startle induced negative geotaxis climbing assay (BRANCO et al. 2008; MADABATTULA et al. 2015), with minor modifications. Three separate sets (biological replicates) of 30 age-matched adult males of each genotype were raised at $25^{\circ} \mathrm{C}$, with 15 males in each vial. Each experimental set of 30 flies was transferred in a $250 \mathrm{ml}(30 \mathrm{~cm})$ glass cylinder and allowed to acclimatise for around 5 minutes. These flies were then tapped to induce a startle and were allowed to climb for $60 \mathrm{~s}$. After $60 \mathrm{~s}$, the flies were scored into three kinds based on their position in the cylinder. Flies which did not climb were scored 0 (Non-Climbers), flies which climbed till $80 \mathrm{~mL}(7.5 \mathrm{~cm})$ mark were scored 1 (Bad Climbers) and flies which climbed beyond $80 \mathrm{~mL}$ were scored 2 (Good Climbers). This was repeated thrice for each set of flies. A three minute resting window was used in between the trials for each genotype. The climbing assays were conducted for a genotype every 5 days till at least one genotype completely stopped climbing or the flies were dead. The flies were exposed to CO2 only after a day's trial was complete, ensuring no effect of anaesthesia on the assay. Flies were transferred to a fresh vial every four days to avoid death due to sticky media. The scores were used to calculate the climbing index of replicates. Statistical analysis was performed using Two-way ANOVA followed by multiple comparison testing by Tukey test. The Climbing index is a proxy for the fitness of a particular fly/genotype on a particular day and can be used as a readout for any progression of the motor defect in a set of flies. The climbing index was calculated as described by (AZUMA et al. 2014).

Microscopy, Staining \& Image analysis: For larval brains, wandering third instar larvae were selected and the brains dissected in phosphate buffer Saline (1X PBS). Fixation was carried out in 4\%PFA with $0.3 \%$ Triton-X in PBS for 20 minutes followed by three washes with $1 \mathrm{X}$ PBS. The brains were blocked 
in $2 \%$ BSA with $0.3 \%$ Triton $\mathrm{X}-100$ in PBS for 1.5 -hours and then incubated in primary antibodies overnight at $4^{\circ} \mathrm{C}$. This was followed by 1.5 - hour wash with blocking solution and incubation in Alexa Fluor secondary antibodies for 1.5 hours at room temperature, followed by four 20 minute washes with the blocking solution. DAPI (4,6 diamidino-2-phenylindole DAPI) was added during the second wash (1:1000). Samples were then washed with PBS, mounted in 70\% glycerol with $n$-propyl gallate and the areas of the ventral nerve cord were imaged under Zeiss Confocal microscopes at $63 \mathrm{X}$ oil magnification. Antibodies utilized are as follows: M Anti-Repo (DSHB; 1:100), Rat Anti-ELAV (DSHB;1:100), Rb AntiVAP (YADAV et al. 2018; CHAPLOT et al. 2019). The analysis was as described earlier (CHAPLOT et al. 2019).

For the adult brains preparations, flies were anaesthetized using $\mathrm{CO} 2$ and their brains dissected in 1X PBS (pH 7.4). The brains were fixed in $1.2 \%$ PFA for 24 hours at $4{ }^{\circ} \mathrm{C}$, then washed twice in 5\% PBST for 20 minutes, followed by two 30 -minute washes in PAT (0.5\% BSA with $0.5 \%$ Triton X-100 in 1X PBS) buffer. The samples were then blocked in 5\% BSA for two hours. The brains were incubated in primary antibody for 36 hours at $4{ }^{\circ} \mathrm{C}$ then washed in PAT Buffer, followed by incubation with secondary antibody for another 36 hours. The samples were washed four times in PAT buffer, 1 hour each wash. DAPI was added during the second wash. Next, samples were washed with PBS, mounted in Slowfade mounting medium (Vectashield, S36937) and imaged. Images were acquired on a Leica Sp8, using a $63 x$ objective with a zoom factor of 0.75 . Z stacks were acquired with an interval of 1 micron at 16-bit depth. Images were analyzed by Huygens Professional software (HuPro CE 18.10.0p2) from Scientific Volume Imaging, as described (CHAPLOT et al. 2019), with modifications. $5-10$ brains were analyzed per experiment with five regions of interest $(\mathrm{ROI})$ per brain. The ROIs were chosen in the sub-esophageal region of the brain. Parameters measured were 'aggregate volume' in $\mu \mathrm{m}^{3}$ and 'aggregate density' as number of aggregates per $\mu \mathrm{m}^{3}$. Data was represented as normalized values to the control ( $\triangle V A P ; R e p o>+; g V A P^{P 58 S}$ ) on each day (Fig. $\left.4 \mathrm{~J}-\mathrm{O}\right)$. Graphpad prism 7 was used to plot the data. For statistical analysis, one- way ANOVA was used followed by Tukey's multiple comparison test statistical significance.

Real-Time PCR: mRNA was extracted from 50-80 adult heads (5-day and 15-day old) using the Qiagen RNAeasy mini kit (74104). 1ug of mRNA was used for the cDNA synthesis using the High Capacity cDNA Reverse Transcriptase Kit (4368814) by Applied Biosystems. The qPCR reaction was carried out using KAPA SYBR FAST (KK4602) by Sigma using Eppendorf Realplex Mastercycler. The experiments were carried out thrice with three technical replicates each. The relative fold change for each genotype was calculated by normalizing to the housekeeping gene rp49. The data was the analysed using Two-way ANOVA followed by Tukey's test for multiple comparison. Primers pairs used (HANDU et al. 2015; KOUNATIDIS et al. 2017) were as follows: rp49 Forward(-f): GACGCTTCAAGGGACAGTATC, rp49 reverse(-r): AAACGCGGTTCTGCATGAG; attacinD-f: CGGTCAACGCCAATGGTCAT, attacinD-r: CATTCAGAGCGGCGTTATTG; diptericin-f: ACCGCAGTACCCACTCAATC, diptericin-r: GGTCCACACCTTCTGGTGAC; cecropinA1-f: CATTGGACAATCGGAAGCTGGGTG, cecropinA1-r: TAATCATCGTGGTCAACCTCGGGC; drosocinf: GTTCACCATCGTTTTCC, drosocin-r: CCACACCCATGGCAAAAAC; metchnikowin-f: GCTACATCAGTGCTGGCAGA, metchnikowin-r: AATAAATTGGACCCGGTCT.

\section{ACKNOWLEDGEMENTS}

We thank: BDSC, supported by NIH grant P40OD018537, for fly stocks; FlyBase, supported by a grant from the National Human Genome Research Institute at the U.S. National Institutes of Health U41HG000739; National Institute Genetics (NIG), Japan, for fly stocks; Drosophila Genome Resource Centre (DGRC), supported by NIH grant 2P40OD010949, for vectors and clones; Transgenic RNAi project (TRiP), at the Harvard Medical School supported by NIH/NIGMS R01-GM084947 for providing transgenic RNAi fly stocks; Transgenic injection facility at the National Centre for Biological Sciences (NCBS); IISER Imaging Facility for access to microscopy and analysis resources; IISER Proteomics facility for training of students and access to instruments; Neel Wagh for technical support. 
Funding: Indian Council for Medical Research (ICMR) \#2020-4887. Department of Biotechnology (DBT), \# BT/PR26095/GET/119/199/2017, Govt. of India. National Facility for Gene Function in Health and Disease (NFGFHD) supported by a DBT grant (BT/INF/22/SP17358/2016). Intramural support from the Agharkar Research Institute, Pune to AR and from IISER, Pune to GSR. ST, AT, LG are graduate students supported by IISER Fellowships, while $\mathrm{SH}$ is supported by a fellowship from the Council for Scientific and Industrial Research (CSIR), Govt. Of India.

Author Contributions: ST and GR conceptualized the project. ST, SH, AT, LG, BK executed the experiments, collected data and analysed the same. AR and GR were involved in supervision, project administration and funding acquisition. All authors contributed to the writing and editing of manuscript.

Competing Interest Statement: The authors have no competing interests. 


\section{REFERENCES}

Abel, O., J. F. Powell, P. M. Andersen and A. Al-Chalabi, 2012 ALSoD: A user-friendly online bioinformatics tool for amyotrophic lateral sclerosis genetics. Human Mutation 33: 13451351.

Albensi, B. C., and M. P. Mattson, 2000 Evidence for the involvement of TNF and NF-kappa B in hippocampal synaptic plasticity. Synapse 35: 151-159.

Azuma, Y., T. Tokuda, M. Shimamura, A. Kyotani, H. Sasayama et al., 2014 Identification of ter94, Drosophila VCP, as a strong modulator of motor neuron degeneration induced by knockdown of Caz, Drosophila FUS. Human Molecular Genetics 23: 3467-3480.

Baron, Y., P. G. Pedrioli, K. Tyagi, C. Johnson, N. T. Wood et al., 2014 VAPB/ALS8 interacts with FFATlike proteins including the p97 cofactor FAF1 and the ASNA1 ATPase. BMC Biol 12: 39.

Bazan, N. G., 2009 Is NF-kappa B from astrocytes a decision maker of neuronal life or death? (Commentary on Dvoriantchikova et al.). European Journal of Neuroscience 30: 173-174.

Beattie, E. C., D. Stellwagen, W. Morishita, J. C. Bresnahan, B. K. Ha et al., 2002 Control of synaptic strength by glial TNF alpha. Science 295: 2282-2285.

Boersma, M. C., and M. K. Meffert, 2008 Novel Roles for the NF-kappa B Signaling Pathway in Regulating Neuronal Function. Science Signaling 1.

Boillee, S., C. Vande Velde and D. W. Cleveland, 2006 ALS: a disease of motor neurons and their nonneuronal neighbors. Neuron 52: 39-59.

Branco, J., I. Al-Ramahi, L. Ukani, A. M. Perez, P. Fernandez-Funez et al., 2008 Comparative analysis of genetic modifiers in Drosophila points to common and distinct mechanisms of pathogenesis among polyglutamine diseases. Human Molecular Genetics 17: 376-390.

Cabukusta, B., I. Berlin, D. M. van Elsland, I. Forkink, M. Spits et al., 2020 Human VAPome Analysis Reveals MOSPD1 and MOSPD3 as Membrane Contact Site Proteins Interacting with FFATRelated FFNT Motifs. Cell Reports 33.

Cao, Y., S. Chtarbanova, A. J. Petersen and B. Ganetzky, 2013 Dnr1 mutations cause neurodegeneration in Drosophila by activating the innate immune response in the brain. Proceedings of the National Academy of Sciences of the United States of America 110: E1752-E1760.

Chai, A., J. Withers, Y. H. Koh, K. Parry, H. Bao et al., 2008 hVAPB, the causative gene of a heterogeneous group of motor neuron diseases in humans, is functionally interchangeable with its Drosophila homologue DVAP-33A at the neuromuscular junction. Hum Mol Genet 17: 266-280.

Chance, P. F., B. A. Rabin, S. G. Ryan, Y. Ding, M. Scavina et al., 1998 Linkage of the gene for an autosomal dominant form of juvenile amyotrophic lateral sclerosis to chromosome 9q34 (vol 62, pg 633, 1998). American Journal of Human Genetics 63: 295-295.

Chang, Y. C., W. T. Hung, Y. C. Chang, H. C. Chang, C. L. Wu et al., 2011 Pathogenic VCP/TER94 Alleles Are Dominant Actives and Contribute to Neurodegeneration by Altering Cellular ATP Level in a Drosophila IBMPFD Model. Plos Genetics 7.

Chaplot, K., L. Pimpale, B. Ramalingam, S. Deivasigamani, S. S. Kamat et al., 2019 SOD1 activity threshold and TOR signalling modulate VAP(P58S) aggregation via reactive oxygen speciesinduced proteasomal degradation in a Drosophila model of amyotrophic lateral sclerosis. Disease Models \& Mechanisms 12.

Chen, L., N. Paquette, S. Mamoor, F. Rus, A. Nandy et al., 2017 Innate immune signaling in Drosophila is regulated by transforming growth factor beta (TGF beta)-activated kinase (Tak1)-triggered ubiquitin editing. Journal of Biological Chemistry 292: 8738-8749.

Chen, P., A. Rodriguez, R. Erskine, T. Thach and J. M. Abrams, 1998 DREDD, a novel effector of the apoptosis activators REAPER, GRIM, and HID in Drosophila. Developmental Biology 201: 202216. 
Chinchore, Y., G. F. Gerber and P. J. Dolph, 2012 Alternative pathway of cell death in Drosophila mediated by NF-kappa B transcription factor Relish. Proceedings of the National Academy of Sciences of the United States of America 109: E605-E612.

Chu, K. T., X. H. Niu and L. T. Williams, 1995 A Fas-Associated Protein Factor, Faf1, Potentiates FasMediated Apoptosis. Proceedings of the National Academy of Sciences of the United States of America 92: 11894-11898.

Cleveland, D. W., and J. D. Rothstein, 2001 From charcot to lou gehrig: deciphering selective motor neuron death in als. Nature Reviews Neuroscience 2: 806-819.

Deivasigamani, S., H. K. Verma, R. Ueda, A. Ratnaparkhi and G. S. Ratnaparkhi, 2014 A genetic screen identifies Tor as an interactor of VAPB in a Drosophila model of amyotrophic lateral sclerosis. Biology Open 3: 1127-1138.

Deng, H. X., A. Hentati, J. A. Tainer, Z. Iqbal, A. Cayabyab et al., 1993 Amyotrophic lateral sclerosis and structural defects in $\mathrm{Cu}, \mathrm{Zn}$ superoxide dismutase. Science 261: 1047-1051.

Di Mattia, T., A. Martinet, S. Ikhlef, A. G. McEwen, Y. Nomine et al., 2020 FFAT motif phosphorylation controls formation and lipid transfer function of inter-organelle contacts. Embo Journal 39.

Diaper, D. C., Y. Adachi, L. Lazarou, M. Greenstein, F. A. Simoes et al., 2013 Drosophila TDP-43 dysfunction in glia and muscle cells cause cytological and behavioural phenotypes that characterize ALS and FTLD. Human Molecular Genetics 22: 3883-3893.

Dickens, L. S., R. S. Boyd, R. Jukes-Jones, M. A. Hughes, G. L. Robinson et al., 2012 A Death Effector Domain Chain DISC Model Reveals a Crucial Role for Caspase-8 Chain Assembly in Mediating Apoptotic Cell Death. Molecular Cell 47: 291-305.

Fasana, E., M. Fossati, A. Ruggiano, S. Brambillasca, C. C. Hoogenraad et al., 2010 A VAPB mutant linked to amyotrophic lateral sclerosis generates a novel form of organized smooth endoplasmic reticulum. FASEB J 24: 1419-1430.

Forrest, S., A. Chai, M. Sanhueza, M. Marescotti, K. Parry et al., 2013 Increased levels of phosphoinositides cause neurodegeneration in a Drosophila model of amyotrophic lateral sclerosis. Hum Mol Genet 22: 2689-2704.

Frakes, A. E., and A. Dillin, 2017 The UPRER: Sensor and Coordinator of Organismal Homeostasis. Molecular Cell 66: 761-771.

Frakes, A. E., L. Ferraiuolo, A. M. Haidet-Phillips, L. Schmelzer, L. Braun et al., 2014 Microglia Induce Motor Neuron Death via the Classical NF-kappa B Pathway in Amyotrophic Lateral Sclerosis. Neuron 81: 1009-1023.

Fu, T. M., Y. Li, A. Lu, Z. L. Li, P. R. Vajjhala et al., 2016 Cryo-EM Structure of Caspase-8 Tandem DED Filament Reveals Assembly and Regulation Mechanisms of the Death-Inducing Signaling Complex. Molecular Cell 64: 236-250.

Fukuyama, H., Y. Verdier, Y. Guan, C. Makino-Okamura, V. Shilova et al., 2013 Landscape of proteinprotein interactions in Drosophila immune deficiency signaling during bacterial challenge. Proceedings of the National Academy of Sciences of the United States of America 110: 10717-10722.

Genevini, P., G. Papiani, A. Ruggiano, L. Cantoni, F. Navone et al., 2014 Amyotrophic lateral sclerosislinked mutant VAPB inclusions do not interfere with protein degradation pathways or intracellular transport in a cultured cell model. PLoS One 9: e113416.

Georgel, P., S. Naitza, C. Kappler, D. Ferrandon, D. Zachary et al., 2001 Drosophila immune deficiency (IMD) is a death domain protein that activates antibacterial defense and can promote apoptosis. Developmental Cell 1: 503-514.

Han, S. M., H. Tsuda, Y. Yang, J. Vibbert, P. Cottee et al., 2012 Secreted VAPB/ALS8 major sperm protein domains modulate mitochondrial localization and morphology via growth cone guidance receptors. Dev Cell 22: 348-362.

Handu, M., B. Kaduskar, R. Ravindranathan, A. Soory, R. Giri et al., 2015 SUMO-Enriched Proteome for Drosophila Innate Immune Response. G3-Genes Genomes Genetics 5: 2137-2154. 
Heckscher, E. S., R. D. Fetter, K. W. Marek, S. D. Albin and G. W. Davis, 2007 NF-kappa B, I kappa B, and IRAK control glutarnate receptor density at the drosophila NMJ. Neuron 55: 859-873.

Hegde, S., A. Soory, B. Kaduskar and G. S. Ratnaparkhi, 2020 SUMO conjugation regulates immune signalling. Fly 14: 62-79.

Hu, S. M., and X. L. Yang, 2000 dFADD, a novel death domain-containing adapter protein for the Drosophila caspase DREDD. Journal of Biological Chemistry 275: 30761-30764.

Kaltschmidt, B., and C. Kaltschmidt, 2009 NF-kappa B in the Nervous System. Cold Spring Harbor Perspectives in Biology 1.

Kamemura, K., and T. Chihara, 2019 Multiple functions of the ER-resident VAP and its extracellular role in neural development and disease. Journal of Biochemistry 165: 391-400.

Kanekura, K., H. Suzuki, S. Aiso and M. Matsuoka, 2009 ER stress and unfolded protein response in amyotrophic lateral sclerosis. Mol Neurobiol 39: 81-89.

Kang, W., and J. K. Yang, 2011 Crystal structure of human FAF1 UBX domain reveals a novel FcisP touch-turn motif in p97/VCP-binding region. Biochemical and Biophysical Research Communications 407: 531-534.

Kim, C. H., D. Paik, F. Rus and N. Silverman, 2014 The Caspase-8 Homolog Dredd Cleaves Imd and Relish but Is Not Inhibited by p35. Journal of Biological Chemistry 289: 20092-20101.

Kim, K. H., W. Kang, S. W. Suh and J. K. Yang, 2011 Crystal structure of FAF1 UBX domain in complex with p97/VCP N domain reveals a conformational change in the conserved FcisP touch-turn motif of UBX domain. Proteins-Structure Function and Bioinformatics 79: 2583-2587.

Kim, M., J. H. Lee, S. Y. Lee, E. Kim and J. Chung, 2006 Caspar, a suppressor of antibacterial immunity in Drosophila. Proceedings of the National Academy of Sciences of the United States of America 103: 16358-16363.

Kleino, A., N. F. Ramia, G. Bozkurt, Y. F. Shen, H. Nailwal et al., 2017 Peptidoglycan-Sensing Receptors Trigger the Formation of Functional Amyloids of the Adaptor Protein Imd to Initiate Drosophila NF-kappa B Signaling. Immunity 47: 635-+.

Kleino, A., and N. Silverman, 2019 Regulation of the Drosophila Imd pathway by signaling amyloids. Insect Biochemistry and Molecular Biology 108: 16-23.

Kounatidis, I., and S. Chtarbanova, 2018 Role of Glial immunity in Lifespan Determination: A Drosophila Perspective. Frontiers in Immunology 9.

Kounatidis, I., S. Chtarbanova, Y. Cao, M. Hayne, D. Jayanth et al., 2017 NF-kappa B Immunity in the Brain Determines Fly Lifespan in Healthy Aging and Age-Related Neurodegeneration. Cell Reports 19: 836-848.

Kuijpers, M., K. L. Yu, E. Teuling, A. Akhmanova, D. Jaarsma et al., 2013 The ALS8 protein VAPB interacts with the ER-Golgi recycling protein YIF1A and regulates membrane delivery into dendrites. Embo Journal 32: 2056-2072.

Larroquette, F., L. Seto, P. L. Gaub, B. Kamal, D. Wallis et al., 2015 Vapb/Amyotrophic lateral sclerosis 8 knock-in mice display slowly progressive motor behavior defects accompanying ER stress and autophagic response. Hum Mol Genet 24: 6515-6529.

Leblond, C. S., H. M. Kaneb, P. A. Dion and G. A. Rouleau, 2014 Dissection of genetic factors associated with amyotrophic lateral sclerosis. Exp Neurol 262 Pt B: 91-101.

Lee, B. P., and B. W. Jones, 2005 Transcriptional regulation of the Drosophila glial gene repo. Mechanisms of Development 122: 849-862.

Lemaitre, B., and J. Hoffmann, 2007 The host defense of Drosophila melanogaster. Annual Review of Immunology 25: 697-743.

Leulier, F., A. Rodriguez, R. S. Khush, J. M. Abrams and B. Lemaitre, 2000 The Drosophila caspase Dredd is required to resist Gram-negative bacterial infection. Embo Reports 1: 353-358.

Lev, S., D. Ben Halevy, D. Peretti and N. Dahan, 2008 The VAP protein family: from cellular functions to motor neuron disease. Trends Cell Biol 18: 282-290. 
Li, Y. X., O. C. M. Sibon and P. F. Dijkers, 2018 Inhibition of NF-kappa B in astrocytes is sufficient to delay neurodegeneration induced by proteotoxicity in neurons. Journal of Neuroinflammation 15.

Ligoxygakis, P., 2013 Genetics of Immune Recognition and Response in Drosophila host defense. Advances in Genetics, Vol 83 83: 71-97.

Lindhout, F. W., Y. J. Cao, J. T. Kevenaar, A. Bodzeta, R. Stucchi et al., 2019 VAP-SCRN1 interaction regulates dynamic endoplasmic reticulum remodeling and presynaptic function. Embo Journal 38.

Loewen, C. J., and T. P. Levine, 2005 A highly conserved binding site in vesicle-associated membrane protein-associated protein (VAP) for the FFAT motif of lipid-binding proteins. J Biol Chem 280: 14097-14104.

Loewen, C. J., A. Roy and T. P. Levine, 2003 A conserved ER targeting motif in three families of lipid binding proteins and in Opi1p binds VAP. EMBO J 22: 2025-2035.

Lubin, F. D., and J. D. Sweatt, 2007 The I kappa B kinase regulates chromatin structure during reconsolidation of conditioned fear memories. Neuron 55: 942-957.

Madabattula, S. T., J. C. Strautman, A. M. Bysice, J. A. O'Sullivan, A. Androschuk et al., 2015 Quantitative Analysis of Climbing Defects in a Drosophila Model of Neurodegenerative Disorders. Jove-Journal of Visualized Experiments.

Mao, D. X., G. Lin, B. Tepe, Z. Y. Zuo, K. Li Tan et al., 2019 VAMP associated proteins are required for autophagic and lysosomal degradation by promoting a PtdIns4P-mediated endosomal pathway. Autophagy 15: 1214-1233.

Meffert, M. K., and D. Baltimore, 2005 Physiological functions for brain NF-kappa B. Trends in Neurosciences 28: 37-43.

Meinander, A., C. Runchel, T. Tenev, L. Chen, C. H. Kim et al., 2012 Ubiquitylation of the initiator caspase DREDD is required for innate immune signalling. Embo Journal 31: 2770-2783.

Menges, C. W., D. A. Altomare and J. R. Testa, 2009 FAS-associated factor 1 (FAF1) Diverse functions and implications for oncogenesis. Cell Cycle 8: 2528-2534.

Min-Young, P., M. Ji-Hyun and K. Eunhee, 2004 Fas associated factor 1, FAF1, impairs NF-kappaB activation by interacting with the IkappaB kinase complex. Molecular Biology of the Cell 15: 17a-17a.

Mitchell, J. D., and G. D. Borasio, 2007 Amyotrophic lateral sclerosis. Lancet 369: 2031-2041.

Mori, A., S. Yamashita, K. Uchino, T. Suga, T. Ikeda et al., 2011 Derlin-1 overexpression ameliorates mutant SOD1-induced endoplasmic reticulum stress by reducing mutant SOD1 accumulation. Neurochemistry International 58: 344-353.

Moumen, A., I. Virard and C. Raoul, 2011 Accumulation of Wildtype and ALS-Linked Mutated VAPB Impairs Activity of the Proteasome. Plos One 6.

Moustaqim-Barrette, A., Y. Q. Lin, S. Pradhan, G. G. Neely, H. J. Bellen et al., 2014 The amyotrophic lateral sclerosis 8 protein, VAP, is required for ER protein quality control. Hum Mol Genet 23: 1975-1989.

Murphy, S. E., and T. P. Levine, 2016 VAP, a Versatile Access Point for the Endoplasmic Reticulum: Review and analysis of FFAT-like motifs in the VAPome. Biochim Biophys Acta 1861: 952961.

Myllymaki, H., S. Valanne and M. Ramet, 2014 The Drosophila Imd Signaling Pathway. Journal of Immunology 192: 3455-3462.

Nguyen, M. D., J. P. Julien and S. Rivest, 2002 Innate immunity: The missing link in neuroprotection and neurodegeneration? Nature Reviews Neuroscience 3: 216-227.

Nickols, J. C., W. Valentine, S. Kanwal and B. D. Carter, 2003 Activation of the transcription factor NFkappa B in Schwann cells is required for peripheral myelin formation. Nature Neuroscience 6: 161-167.

Nicolas, A., K. P. Kenna, A. E. Renton, N. Ticozzi, F. Faghri et al., 2018 Genome-wide Analyses Identify KIF5A as a Novel ALS Gene. Neuron 97: 1268-+. 
Nishimura, A. L., M. Mitne-Neto, H. C. A. Silva, A. Richieri-Costa, S. Middleton et al., 2004 A Mutation in the Vesicle-Trafficking Protein VAPB Causes Late-Onset Spinal Muscular Atrophy and Amyotrophic Lateral Sclerosis. The American Journal of Human Genetics 75: 822-831.

O'Rourke, J. G., L. Bogdanik, A. Yanez, D. Lall, A. J. Wolf et al., 2016 C9orf72 is required for proper macrophage and microglial function in mice. Science 351: 1324-1329.

ONeill, L. A. J., and C. Kaltschmidt, 1997 NF-kappa B: A crucial transcription factor for glial and neuronal cell function. Trends in Neurosciences 20: 252-258.

Paquette, N., M. Broemer, K. Aggarwal, L. Chen, M. Husson et al., 2010 Caspase-Mediated Cleavage, IAP Binding, and Ubiquitination: Linking Three Mechanisms Crucial for Drosophila NF-kappa B Signaling. Molecular Cell 37: 172-182.

Park, M. Y., J. H. Moon, K. S. Lee, H. I. Choi, J. Chung et al., 2007 FAF1 suppresses I kappa B kinase (IKK) activation by disrupting the IKK complex assembly. Journal of Biological Chemistry 282: 27572-27577.

Pasinelli, P., and R. H. Brown, 2006 Molecular biology of amyotrophic lateral sclerosis: insights from genetics. Nature Reviews Neuroscience 7: 710-723.

Pennetta, G., P. R. Hiesinger, R. Fabian-Fine, I. A. Meinertzhagen and H. J. Bellen, 2002 Drosophila VAP-33A directs bouton formation at neuromuscular junctions in a dosage-dependent manner. Neuron 35: 291-306.

Petersen, A. J., R. J. Katzenberger and D. A. Wassarman, 2013 The Innate Immune Response Transcription Factor Relish Is Necessary for Neurodegeneration in a Drosophila Model of Ataxia-Telangiectasia. Genetics 194: 133-+.

Rappsilber, J., M. Mann and Y. Ishihama, 2007 Protocol for micro-purification, enrichment, prefractionation and storage of peptides for proteomics using StageTips. Nature Protocols 2: 1896-1906.

Ratnaparkhi, A., G. M. Lawless, F. E. Schweizer, P. Golshani and G. R. Jackson, 2008 A Drosophila Model of ALS: Human ALS-Associated Mutation in VAP33A Suggests a Dominant Negative Mechanism. PLoS ONE 3: e2334.

Renton, A. E., A. Chio and B. J. Traynor, 2014 State of play in amyotrophic lateral sclerosis genetics. Nat Neurosci 17: 17-23.

Ritson, G. P., S. K. Custer, B. D. Freibaum, J. B. Guinto, D. Geffel et al., 2010 TDP-43 Mediates Degeneration in a Novel Drosophila Model of Disease Caused by Mutations in VCP/p97. Journal of Neuroscience 30: 7729-7739.

Robberecht, W., and T. Philips, 2013 The changing scene of amyotrophic lateral sclerosis. Nature Reviews Neuroscience 14: 248-264.

Rolls, A., R. Shechter, A. London, Y. Ziv, A. Ronen et al., 2007 Toll-like receptors modulate adult hippocampal neurogenesis. Nature Cell Biology 9: 1081-U1061.

Rosen, D. R., T. Siddique, D. Patterson, D. A. Figlewicz, P. Sapp et al., 1993 Mutations in Cu/Zn superoxide dismutase gene are associated with familial amyotrophic lateral sclerosis. Nature 362: 59-62.

Ruggiano, A., O. Foresti and P. Carvalho, 2014 ER-associated degradation: Protein quality control and beyond. Journal of Cell Biology 204: 868-878.

Ryu, S. W., S. J. Lee, M. Y. Park, J. Jun, Y. K. Jung et al., 2003 Fas-associated factor 1, FAF1, is a member of Fas death-inducing signaling complex. Journal of Biological Chemistry 278: 24003-24010.

Sanhueza, M., A. Chai, C. Smith, B. A. McCray, T. I. Simpson et al., 2015 Network Analyses Reveal Novel Aspects of ALS Pathogenesis. PLoS Genet 11: e1005107.

Sears, C., J. Olesen, D. Rubin, D. Finley and T. Maniatis, 1998 NF-kappa B p105 processing via the ubiquitin-proteasome pathway. Journal of Biological Chemistry 273: 1409-1419.

Shevchenko, A., H. Tomas, J. Havlis, J. V. Olsen and M. Mann, 2006 In-gel digestion for mass spectrometric characterization of proteins and proteomes. Nature Protocols 1: 2856-2860. 
Sochocka, M., B. S. Diniz and J. Leszek, 2017 Inflammatory Response in the CNS: Friend or Foe? Molecular Neurobiology 54: 8071-8089.

Stoven, S., I. Ando, L. Kadalayil, Y. Engstrom and D. Hultmark, 2000 Activation of the Drosophila NFkappa B factor Relish by rapid endoproteolytic cleavage. Embo Reports 1: 347-352.

Swarup, V., D. Phaneuf, C. Bareil, J. Robertson, G. A. Rouleau et al., 2011 Pathological hallmarks of amyotrophic lateral sclerosis/frontotemporal lobar degeneration in transgenic mice produced with TDP-43 genomic fragments. Brain 134: 2610-2626.

Teuling, E., S. Ahmed, E. Haasdijk, J. Demmers, M. O. Steinmetz et al., 2007 Motor Neuron DiseaseAssociated Mutant Vesicle-Associated Membrane Protein-Associated Protein (VAP) B Recruits Wild-Type VAPs into Endoplasmic Reticulum-Derived Tubular Aggregates. Journal of Neuroscience 27: 9801-9815.

Tsuda, H., S. M. Han, Y. Yang, C. Tong, Y. Q. Lin et al., 2008 The Amyotrophic Lateral Sclerosis 8 Protein VAPB Is Cleaved, Secreted, and Acts as a Ligand for Eph Receptors. Cell 133: 963-977.

van Blitterswijk, M., M. A. van Es, E. A. Hennekam, D. Dooijes, W. van Rheenen et al., 2012 Evidence for an oligogenic basis of amyotrophic lateral sclerosis. Hum Mol Genet 21: 3776-3784.

van den Boom, J., and H. Meyer, 2018 VCP/p97-Mediated Unfolding as a Principle in Protein Homeostasis and Signaling. Molecular Cell 69: 182-194.

Vance, C., B. Rogelj, T. Hortobagyi, K. J. De Vos, A. L. Nishimura et al., 2009 Mutations in FUS, an RNA processing protein, cause familial amyotrophic lateral sclerosis type 6 . Science 323: 1208 1211.

Vembar, S. S., and J. L. Brodsky, 2008 One step at a time: endoplasmic reticulum-associated degradation. Nature Reviews Molecular Cell Biology 9: 944-U930.

Yadav, S., R. Thakur, P. Georgiev, S. Deivasigamani, H. Krishnan et al., 2018 RDGBalpha localization and function at membrane contact sites is regulated by FFAT-VAP interactions. J Cell Sci 131.

Yeung, H. O., P. Kloppsteck, H. Niwa, R. L. Isaacson, S. Matthews et al., 2008 Insights into adaptor binding to the AAA protein p97. Biochemical Society Transactions 36: 62-67.

Zaman, M. F., A. Nenadic, A. Radojicic, A. Rosado and C. T. Beh, 2020 Sticking With It: ER-PM Membrane Contact Sites as a Coordinating Nexus for Regulating Lipids and Proteins at the Cell Cortex. Frontiers in Cell and Developmental Biology 8.

Zhai, Z. Z., X. S. Huang and Y. L. Yin, 2018 Beyond immunity: The Imd pathway as a coordinator of host defense, organismal physiology and behavior. Developmental and Comparative Immunology 83: 51-59.

Zhang, X. Y., L. Gui, X. Y. Zhang, S. L. Bulfer, V. Sanghez et al., 2015 Altered cofactor regulation with disease-associated p97/VCP mutations. Proceedings of the National Academy of Sciences of the United States of America 112: E1705-E1714.

Zhou, R., N. Silverman, M. Hong, D. S. Liao, Y. Chung et al., 2005 The role of ubiquitination in Drosophila innate immunity. Journal of Biological Chemistry 280: 34048-34055. 

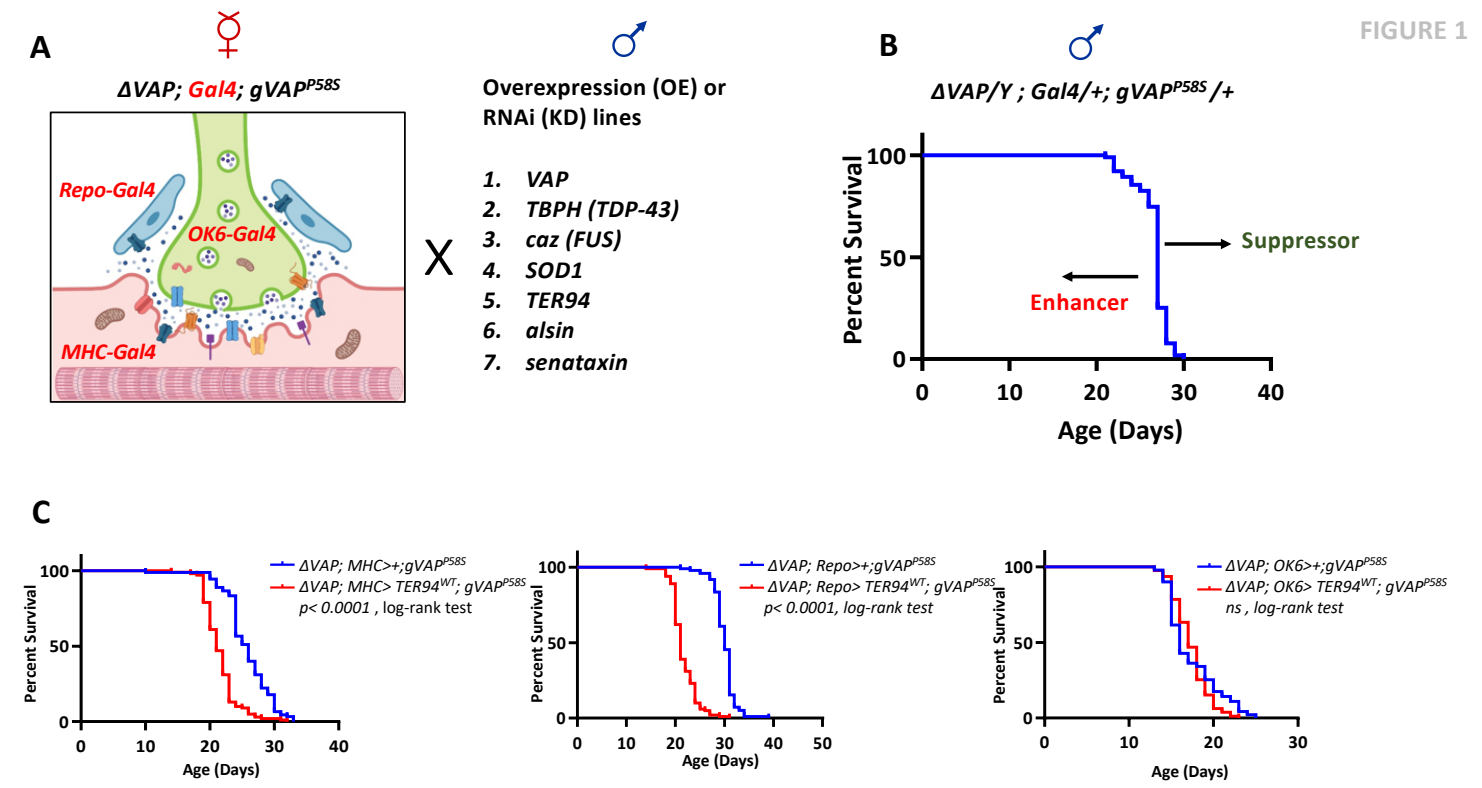

D

\begin{tabular}{|c|c|c|c|c|c|c|c|}
\hline ALS Loci & \multicolumn{2}{|c|}{ Muscle } & \multicolumn{2}{|c|}{ Glia } & \multicolumn{2}{|c|}{ Motor Neurons } & \multirow{3}{*}{$\begin{array}{l}\text { Key } \\
\text { E= Enhancers } \\
S=\text { Suppressors }\end{array}$} \\
\hline & $\mathrm{OE}$ & $\mathrm{KD}$ & $\mathrm{OE}$ & KD & $\mathrm{OE}$ & $\mathrm{KD}$ & \\
\hline & \multicolumn{6}{|c|}{$\Delta \mathrm{ML}$} & \\
\hline VAP & -5 & -3 & -7 & -4 & +1.5 & +4 & $<0.0011^{* * * *}$ \\
\hline TBPH (TDP43) & -5 & -3 & -3 & -3 & +2 & +3 & $<0.011^{(* *)}$ \\
\hline \multirow{2}{*}{$c a z$ (FUS) } & \multirow{2}{*}{ - } & \multirow{2}{*}{-3} & \multirow{2}{*}{ - } & \multirow{2}{*}{+1} & \multirow{2}{*}{ - } & \multirow{2}{*}{+4} & $<0.05\left(^{*}\right)$ \\
\hline & & & & & & & $>0.05$ \\
\hline SOD1 & -5 & -5 & -5 & -1 & +3 & +1 & $\begin{array}{c}\mathrm{s} \\
<0.05\left(^{*}\right)\end{array}$ \\
\hline TER94 (VCP) & -5 & -6 & -9 & 0 & +1 & +1 & $\underset{<0.01(* *)}{s}$ \\
\hline alsin & -2 & -3 & -5 & 0 & +3 & +2 & $\begin{array}{c}5 \\
<0.001(* * *)\end{array}$ \\
\hline senataxin & - & -4 & - & 0 & - & +1 & Log-Rank test \\
\hline
\end{tabular}

Figure 1. An enhancer/suppressor screen for genetic interaction between ALS orthologous loci in neurons, muscle and glia.

A. Tissue specific expression in muscle ( $\left.\triangle V A P ; M H C-G a l 4 ; g V A P^{P 585}\right)$, glia $\left(\triangle V A P ;\right.$ Repo-Gal4; gVAP $\left.{ }^{P 585}\right)$ and motor neurons ( $\triangle V A P$; OK6-Gal4; gVAP ${ }^{P 85}$ ) was used to overexpress and knockdown VAP, TBPH, caz, SOD1, TER94, alsin and senataxin.

B. A schematic for monitoring survival of male animals emerging from the crosses described in panel $A$. The blue curve represents the control $\triangle V A P / Y ; X-G a l 4 /+; g V A P^{P 585} /+$ fly line i.e. $\triangle V A P / Y ; M H C-G a l 4 /+; g V A P^{P 585} /+$ for the muscle-specific screen, $\triangle V A P / Y ;$ Repo-Gal4/+; gVAP $585 /+$ for the glial-specific screen and $\triangle V A P / Y ; O K 6-G a / 4 /+$; $g V A P^{P 585} /+$ for the motor neuron-specific screen. A shift from the lifespan of the control to the right was defined as a 'suppression' of the phenotype while towards the left as 'enhancement'. The survival analysis was done using the log-rank test survival assay protocol, in Prism 7, over the entire dataset, where each curve was compared to the control and the value of significance was noted. This number is reported (Suppl. Fig. 1) and is represented as a colour code in panel $\mathrm{D}$. Additionally, we considered values of $\triangle \mathrm{ML}$ (Change in Median Lifespan $(\mathrm{ML}))=\mathrm{ML}$ (Experiment) $-\mathrm{ML}$ (Control) as a simple readout of enhancement or suppression.

C. Representative graphs for muscle, glial and motor neuronal overexpression of TER94. The red curve represents the locus studied (TER94). The $p$-value from the log-rank test listed in each graph is the comparison of the red curve with the blue curve (control). The muscle and glial overexpression of TER94 exhibit enhancement of life span defect ( $p<0.0001$; log-rank test) while motor neuronal expression shows no significant change. A complete set of graphs (muscle, glia, neurons) for $K D$ and $O E$ of all seven genes can be found in Suppl. Fig. 1.

D. Tabular summary of the tissue-specific screen highlights differential interaction of genetic loci with VAP ${ }^{P 58 S}$. 
bioRxiv preprint doi: https://doi.org/10.1101/2021.04.07.438776; this version posted April 8, 2021. The copyright holder for this preprint (which was not certified by peer review) is the author/funder, who has granted bioRxiv a license to display the preprint in perpetuity. It is made available under aCC-BY-ND 4.0 International license.

The numbers in each cell indicate the $\Delta \mathrm{ML}$, while the colours indicate different levels of statistical confidence, as per the log-rank test. The 'red-yellow tones' mark Enhancers (E) while the 'green tones' represent the same for Suppressors (S). '-' in the cell indicates that the experiment was not done. The caz overexpression construct is an insert on the $X$ chromosome of the fly line and hence could not be used for male specific assay, while for senataxin, the OE line was not available. 'OE' stands for overexpression using UAS lines and 'KD' stands for knockdown, using RNA interference. 
A

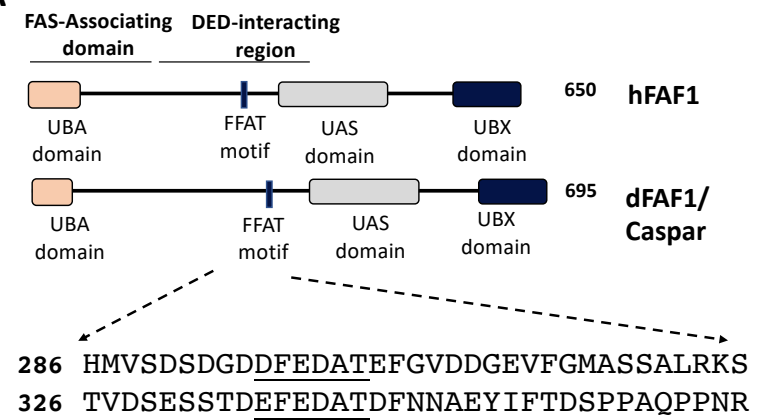

B
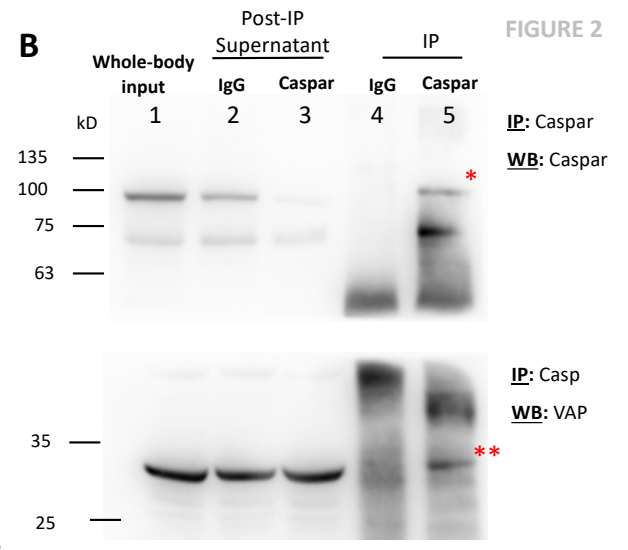

C
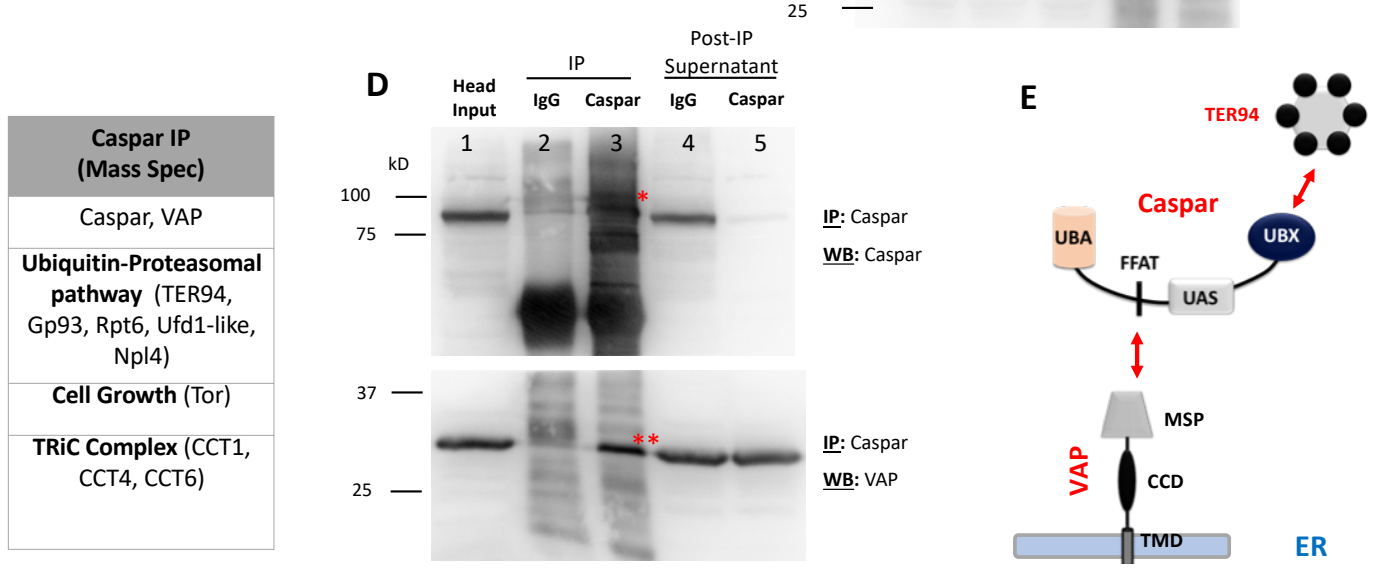

Figure 2. Drosophila Caspar is a physical interactor of VAP.

A. Drosophila Caspar is an ortholog of human FAF1. The conserved N-terminal Ub-interacting and C-terminal TER94 interacting domains suggest roles for Caspar as an adapter in the proteasomal degradation. A conserved FFAT motif (amino acids underlined), which is a well characterized VAP interactor is present in both polypeptides. This suggests that FFAT motif in Caspar may be the interface for an interaction with VAP.

B. An antibody against full length Caspar was generated (Materials and Methods) and validated (Suppl. Figure 2). When used for immunoprecipitation (IP) of whole animal lysates, the Rb Caspar antibody could affinity purify Caspar (*, $90 \mathrm{kD}$, lane 5, top panel) and also VAP (**, $25 \mathrm{kD}$, lane 5, bottom Panel). A concomitant decrease in Caspar in the supernatant (lane 3, top panel) is also seen, post IP. The $\sim 70 \mathrm{kD}$ reactive band is a feature of Caspar westerns.

C. TER94, Gp93, Rpt6, Tor, CCT1 and CCT4 are detected by Mass Spectrometry in the Caspar antibody immuneprecipitates, using whole-body and embryonic lysates (Suppl. Table 1). Many of these are functionally associated with the ubiquitin-proteasomal system (UPS).

D. Caspar immune-precipitates using fly head lysates confirm that Caspar $\left({ }^{*}\right)$ is expressed in the head and can be enriched by the Caspar antibody (lane 3, top panel). Also, VAP $\left.{ }^{* *}\right)$ is a Caspar interactor (lane3, bottom panel). A concomitant decrease in Caspar in the supernatant (lane 5, top panel) is seen, post IP. Further support for the Caspar:VAP interaction comes from a 'reverse' IP experiment where an anti-VAP antibody is used for immunoprecipitation and Caspar is enriched (Suppl. Fig. 2C).

E. A model for the interaction of VAP, an ER resident membrane protein, with cytoplasmic Caspar. Mass spectrometry interaction data suggests that TER94 and other proteins of the UPS are part of Caspar protein:protein interaction network in the cell. 
A

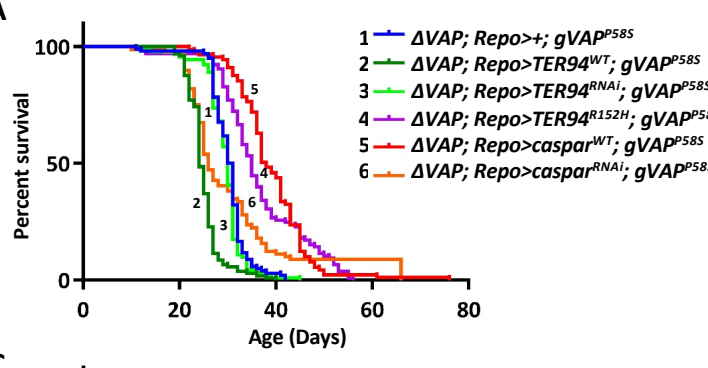

C

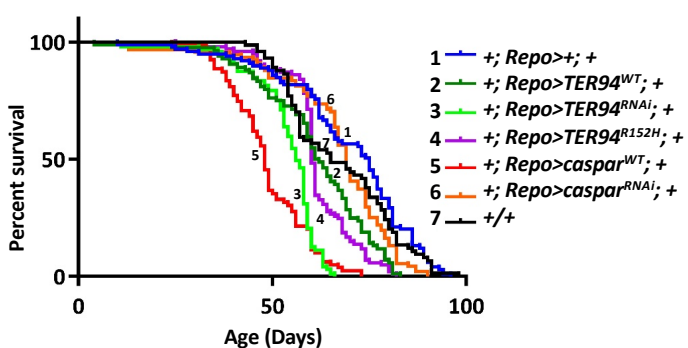

B

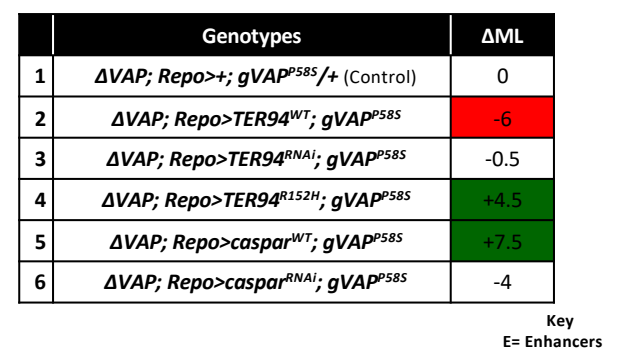

D

\begin{tabular}{|c|c|c|c|}
\hline & Genotypes & $\Delta \mathrm{ML}$ & $=$ Suppressor \\
\hline 1 & +; Repo >+; + (control) & 0 & \\
\hline 2 & + ; Repo>TER94 ${ }^{W T} ;+$ & -3.5 & $<0.011^{\left(*^{* *}\right)}$ \\
\hline 3 & $+: R e p O>T E R 94^{R N A i}++$ & -9 & $<0.05\left({ }^{\circ}\right)$ \\
\hline & & & $>0.05$ \\
\hline & +; керо>1Еку4 ; + & -5 & $\begin{array}{c}5 \\
\left.<0.05 *^{*}\right)\end{array}$ \\
\hline 5 & +; Repo>caspar ${ }^{W T} ;+$ & -17 & $\mathrm{~s}$ \\
\hline 6 & +; Repo>caspar ${ }^{R N A i} ;+$ & +4 & \\
\hline
\end{tabular}

$\mathbf{E}$

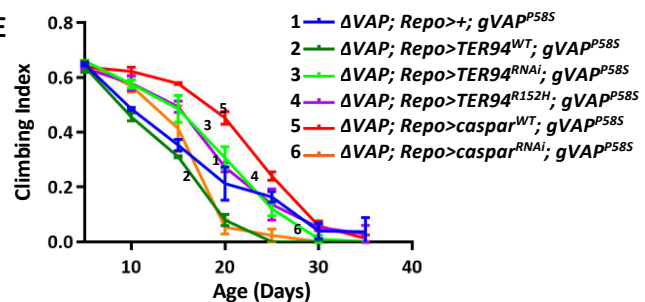

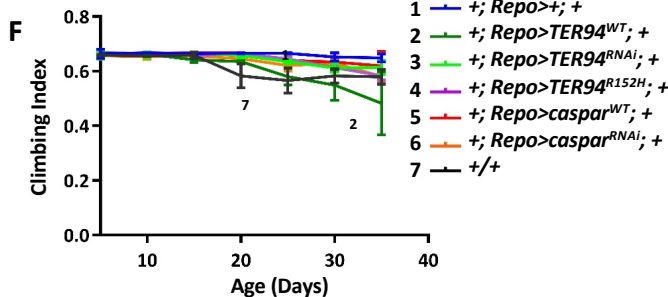

$p$ value for Intervals

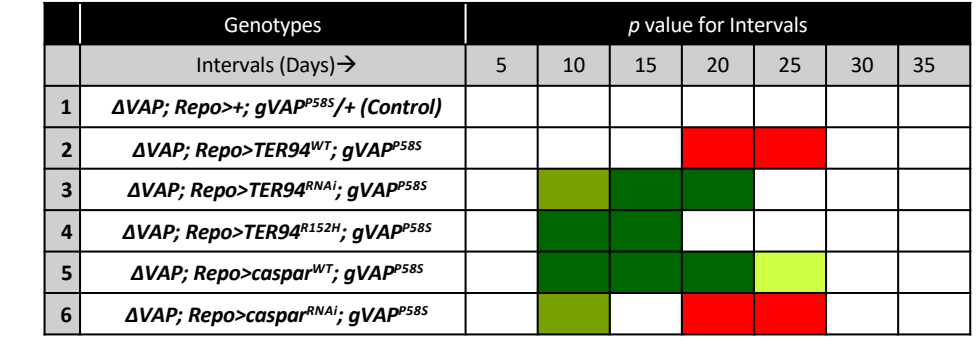

H

\begin{tabular}{|c|c|c|c|c|c|c|c|c|}
\hline & Genotypes & \multicolumn{7}{|c|}{$p$ value for Intervals } \\
\hline & Intervals (Days) $\rightarrow$ & 5 & 10 & 15 & 20 & 25 & 30 & 35 \\
\hline 1 & +; Repo>+; + (control) & & & & & & & \\
\hline 2 & +; Repo>TER94 ${ }^{W T} ;++$ & & & & & & & \\
\hline 3 & $+;$ Repo $>$ TER94 $4^{\text {RNAi } ;+}$ & & & & & & & \\
\hline 4 & +; Repo>TER944 ${ }^{R 152 H} ;+$ & & & & & & & \\
\hline 5 & $+; R e p o>c a s p a r^{W T} ;+$ & & & & & & & \\
\hline 6 & $+;$ Repo>caspar $^{\text {RNAi; }}$ + & & & & & & & \\
\hline
\end{tabular}

Key

E= Enhancers
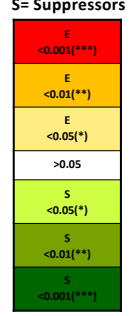

Log-Rank test

Figure 3. Overexpression of caspar in the glia increases lifespan and delays motor dysfunction in the disease model.

A. Lifespan curves for overexpression of TER94 ${ }^{W T}$ (2, Dark green curve), TER94 ${ }^{\text {RNAi }}$ (3, light green), TER94 ${ }^{R 152 H}$ (4, purple), $\operatorname{caspar}^{W T}\left(5\right.$, red) and $\operatorname{Caspar}^{\text {RNAi }}$ (6, orange). $\triangle V A P / Y ;$ Repo>+; gVAPP58S $/+(1$, blue, ML=30.5 days) was used as the control. $n=\sim 100$ flies for every genotype. Curve comparison was done using Log-rank test. Combined $p$-value for the whole set is $<0.001$. For both TER94 ${ }^{R 152 H}$ and caspar ${ }^{W T}$ overexpression, there is an increase in lifespan.

B. Tabulated results for lifespan recordings in panel A, quantified in the form of $\Delta \mathrm{ML}$. The colour codes are as described previously (Fig 1D).

C. Lifespan curves for overexpression of TER94 ${ }^{W T}$ (2, dark green curve), TER94 ${ }^{R N A i}$ (3, light green), TER94 ${ }^{R 152 H}(4$, purple), $\operatorname{caspar}^{W T}\left(5\right.$, red) and caspar ${ }^{R N A i}$ (6, orange) using +; Repo-Gal4; + background. +; Repo>+;+ (Curve 1 in blue color, ML= 75) was the control for curves $2-6$, while $+/+$ (wild type flies, black curve, 7 ) was used as the 
bioRxiv preprint doi: https://doi.org/10.1101/2021.04.07.438776; this version posted April 8, 2021. The copyright holder for this preprint (which was not certified by peer review) is the author/funder, who has granted bioRxiv a license to display the preprint in perpetuity. It is made available under aCC-BY-ND 4.0 International license.

master control ( $M L=65$ Days) to compare with curve 1 ( $p>0.05$, not significant). Figure $C$ functions as the control for the respective gene specific expressions in Figure $A . n=\sim 100$ flies for every genotype. Curve comparison was done using the Log-rank test. Combined $p$-value for the whole set is $<0.001$.

D. Tabulated results for lifespan recordings in panel C, quantified in the form of $\Delta \mathrm{ML}$. The colour codes are as described previously.

E. Climbing indices for glial OE of TER94 ${ }^{W T}$ (2, dark green curve), TER94 ${ }^{R N A i}$ (3, light green), TER94 ${ }^{R 152 H}$ (4, purple), $\operatorname{caspar}^{W T}\left(5\right.$, red) and caspar ${ }^{R N A i}\left(6\right.$, orange). $\triangle V A P$; Repo $>+; g V A P^{P 58 S} /+(1$, blue color) was used as the control. The individual $p$-values are listed in panel G. For both TER94 ${ }^{R 152 H}$ and caspar $^{W T} \mathrm{OE}$, there is an age dependant improvement in motor function.

F. Climbing indices for glial overexpression of TER94 ${ }^{W T}$ (2, dark green curve), TER94 ${ }^{R N A i}$ (3, light green), TER94 ${ }^{R 152 H}$ $\left(4\right.$, purple), caspar $^{W T}\left(5\right.$, red) and caspar ${ }^{R N A i}(6$, orange) in the wild type background. +; Repo>+; + (1, blue color) was the control for curve 2-6, The individual $p$-values are listed in panel H. +/+ (wild type flies, black curve, number 7) was used as the master control to compare curve 1 , the $p$-values for this comparison were: Day 5 , $p>0.05$ (ns, not significant), Day 10, $p>0.05$ (ns), Day 15, $p>0.05$ (ns), Day 20, $p>0.01\left({ }^{* *}\right)$, Day 25, $p>0.001(* * *)$, Day 30, $p>0.05(*)$ and Day $35, p>0.05\left(^{*}\right)$.

G. Individual $p$-values for intervals (5-day) for the climbing index of the animals in the $\triangle V A P$; Repo-Gal4; gVAP ${ }^{P 585}$ background are plotted as a colour code. As compared to control (row 1), caspar ${ }^{W T}$ overexpression leads to improved motor activity in the age range 10-25 days, while for TER94 ${ }^{R 152 H}$, the period is 10-15 days. H. Individual $p$-values for intervals (5-day) for the climbing index of the animals in the Repo-Gal4 background . As compared to control (row 1), caspar ${ }^{W T}$ overexpression does not improve motor activity in the age range 1-30 days. 

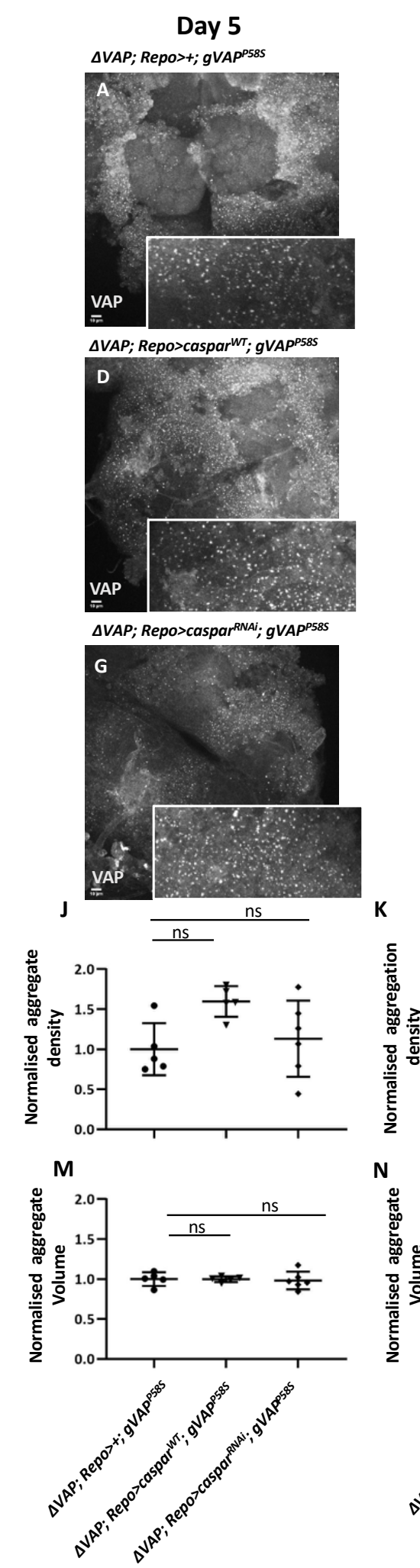

Day 15
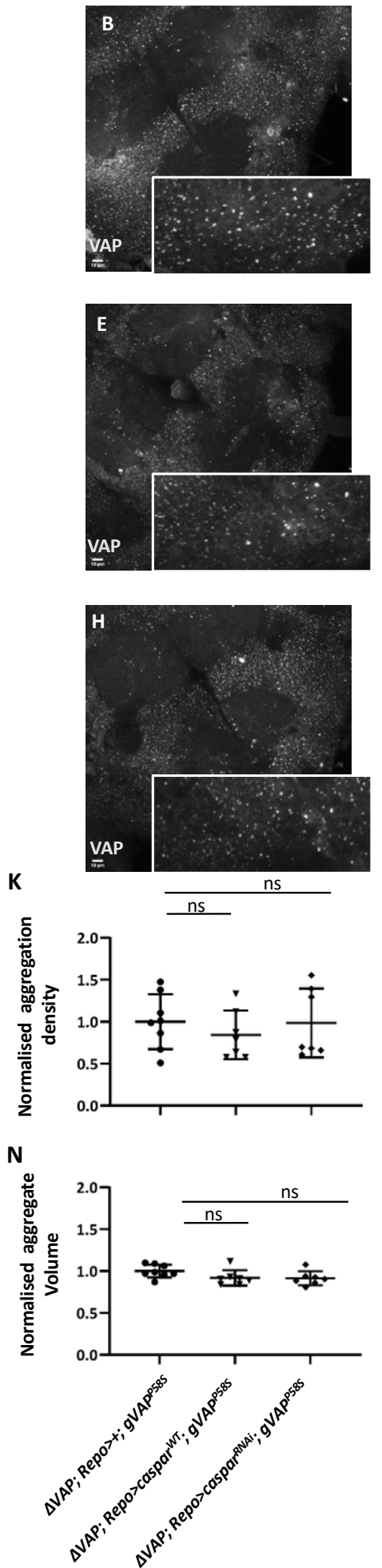

Day 30
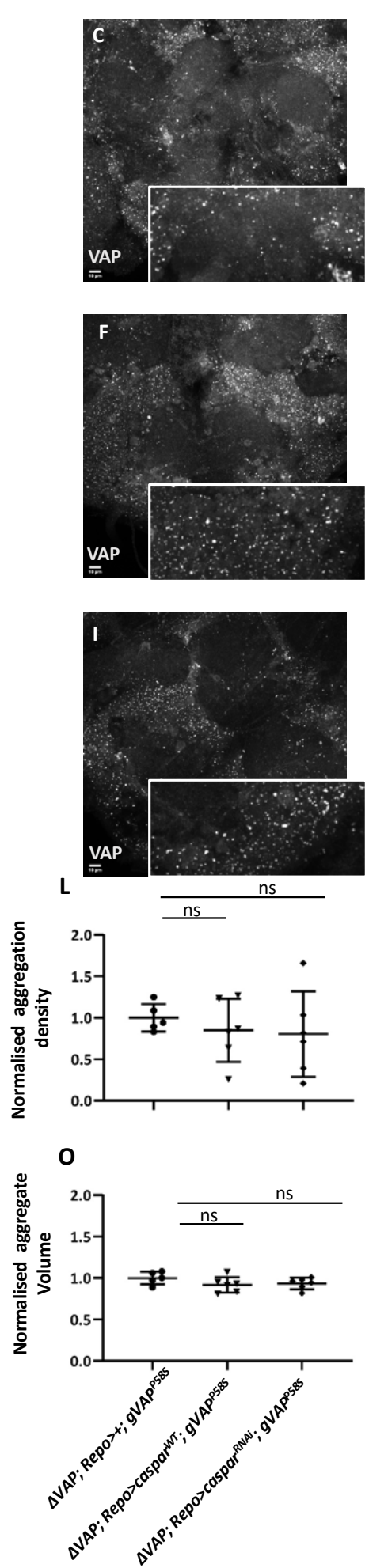

Figure 4. VAP inclusions in the brain of adult animals maintain status-quo in response to caspar overexpression. Representative images of VAP protein inclusions in adult brains for days 5, 15 and 30 . The inclusions are marked with an anti-VAP antibody. The scale bar for the image is $10 \mu \mathrm{m}$. The inclusions are highlighted ( $2 X$ digital zoom) in the inserted panel for each image.

A-C. $\triangle V A P$; Repo $>+; g V A P^{P 58 S}$.

D-F. $\triangle V A P ;$ Repo $>\operatorname{caspar}^{R N A i} ; g V A P^{P 58 S}$ 
bioRxiv preprint doi: https://doi.org/10.1101/2021.04.07.438776; this version posted April 8, 2021. The copyright holder for this preprint (which was not certified by peer review) is the author/funder, who has granted bioRxiv a license to display the preprint in perpetuity. It is made available under aCC-BY-ND 4.0 International license.

G-I. $\triangle V A P ;$ Repo>caspar ${ }^{W T} ;$ gVAP P58s

J-O. Graphical representation of normalised 'aggregate density' (J-L) and normalised 'aggregate volume' (M-O) of VAP inclusions, as defined in Materials and Methods. The genotypes compared are $\triangle V A P$; Repo>+; gVAPP58S /+ (control), $\triangle V A P ;$ Repo >casparWT; gVAPP58S, and $\triangle V A P ;$ Repo $^{2}$ caspar $^{R N A i} ; g V A P^{P 585} . \mathrm{n}=5-10$ brain samples. One-way ANOVA followed by Tukey's multiple comparison ( ${ }^{*} P<0.05,{ }^{* * *} P<0.001, * * * * P<0.0001 ; n s$, not significant). Error bars indicate s.d. 
A

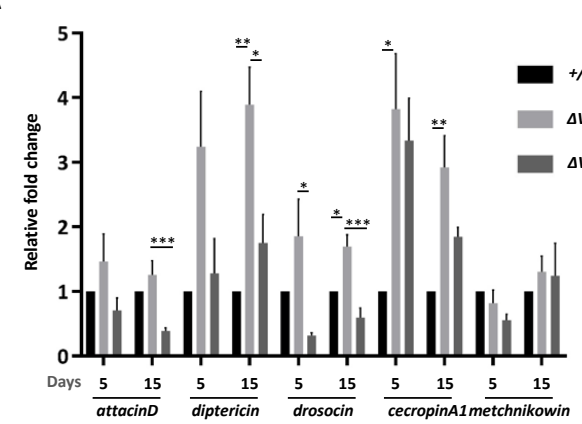

C

\begin{tabular}{|c|c|c|}
\hline & Genotypes & $\Delta M \mathrm{ML}$ \\
\hline 1 & $\triangle V A P ;$ Repo>+; gVAPP5ss/+ (Control) & 0 \\
\hline 2 & $\triangle V A P ; R e p o>R e^{W T} ;$ gVAPPsss & -6 \\
\hline 3 & $\triangle V A P ;$ Repo>RRePNAa; , gVAPPSSSS & +4 \\
\hline 4 & $\triangle V A P ; R e l^{\mid 20 /+;}$ gVAPP58S & -4 \\
\hline 5 & 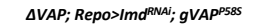 & +4 \\
\hline 6 & 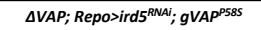 & +2 \\
\hline 7 & 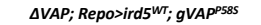 & -4 \\
\hline 8 & $\triangle V A P ;$ Repo>Dredd RNAi; gVAPP58S & -5 \\
\hline 9 & $\triangle V A P ;$ RepoOPPGRP-LCWT; $; V A P^{P S S S S}$ & +1 \\
\hline 10 & $\triangle V A P ;$ Repo>PGRP-LERAa; , VVAPPSSS & \\
\hline
\end{tabular}

B

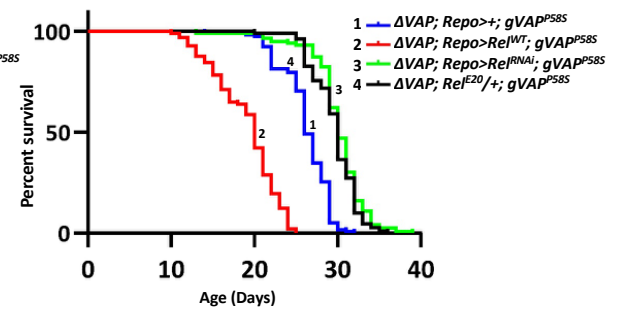

D

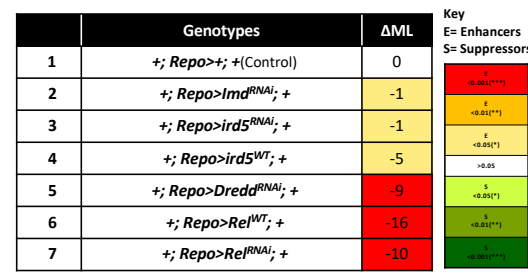

$\mathrm{E}$

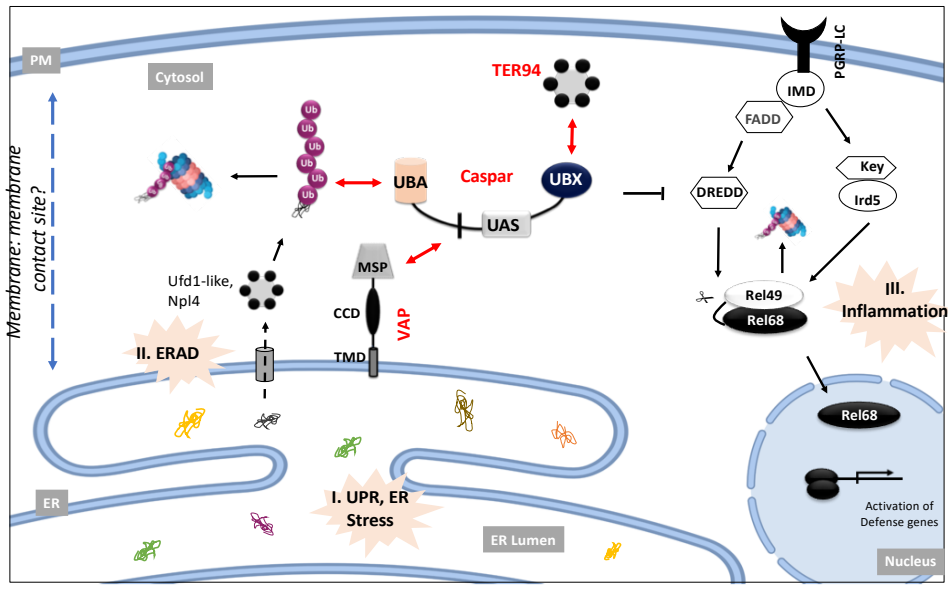

Figure 5. Inflammation in glia, regulated by IMD/Rel signalling contributes to the progression of the disease.

A. Expression of Rel target genes attacinD , diptericin, drosocin, cecropinA1 and Toll pathway target metchnikowin in day-5 and day-15 adult heads of wild type $(+/+), \triangle V A P$; Repo $>+; g V A P^{P 58 S}$ and $\triangle V A P$;

Repo>caspar ${ }^{W T} ; g V A P^{P 58 S}$ lines. Values on the Y-axis depict the fold change normalized to the house keeping gene $r p 49$. Values shown are mean \pm SEM. $N=3, n=3$. Statistical analysis by two-way ANOVA followed by Tukeys multiple comparison test. ${ }^{*} p<0.05, * * p<0.01, * * * p<0.001$.

B. Lifespan plots for overexpression of $R E L^{W T}$ (2, red curve), $R e^{R N A i}$ (3, light green), $R E L^{E 2 O}$ (4, black) in the $\triangle V A P$; Repo-Gal4; gVAP ${ }^{P 58 S}$ genetic background. $\triangle V A P ;$ Repo $>+; g V A P^{P 585} /+(1$, blue curve) was used as the control. Curve comparison was done using log-rank test. Combined $p$-value for the whole set is $<0.001$.

C. Tabulated results $(\triangle \mathrm{ML})$ for lifespan recordings for experiments displayed in panel B and Suppl. Fig 5A. Levels of statistical confidence are color coded. ML for control, $\triangle V A P ; R e p o>+; g V A P^{P 58 S} /+$, is 26 days.

D. Tabulated results $(\triangle \mathrm{ML})$ for lifespan recordings for controls as shown in Suppl. Fig $5 B$. Levels of statistical confidence are color coded.

E. VAP ${ }^{\text {P58S }}$ disease model depicting the involvement of the VAP:Caspar:TER94 interaction in glial proteostasis, and its connectivity with IMD/Rel signalling, which regulates inflammation. The association of Caspar with both ER-based VAP and the PM based IMD/Rel Signalosome suggests that the ER:PM membrane contact sites may 
bioRxiv preprint doi: https://doi.org/10.1101/2021.04.07.438776; this version posted April 8, 2021. The copyright holder for this preprint (which was not certified by peer review) is the author/funder, who has granted bioRxiv a license to display the preprint in perpetuity. It is made available under aCC-BY-ND 4.0 International license.

be the site for Caspar function. The key features of the model include (I) ER Stress caused directly or indirectly VAP misfolding (II) An up-regulation of the protein degradation machinery in response to ER Stress. VAP appears to act as a docking station, interacting with Caspar and TER94 to assist in proteasomal clearance. The AAA-ATPase TER94, itself an ALS locus, plays a central role for this function. (III) Age dependant Inflammation, caused by mis-regulation of Imd/Rel signalling. Our model suggests that Caspar's function as a negative regulator for Imd/Rel signalling is attenuated in the disease. This may be a consequence of an increased partitioning of the available glial Caspar pool for VAP or TER94 related functions. As the adult animal ages, a tipping point is reached when the increasing burden of ER stress, proteasomal overload and glial inflammation leads to motor neuron cell death, followed by the death of the organism. 